\title{
Transcriptome comparative analysis of ovarian follicles reveals the key genes and signaling pathways implicated in hen egg production
}

Xue Sun ${ }^{1,2+}$, Xiaoxia Chen ${ }^{1,2+}$, Jinghua Zhao ${ }^{1,2}$, Chang Ma ${ }^{1,2}$, Chunchi Yan ${ }^{1,2}$, Simushi Liswaniso ${ }^{1,2}$, Rifu Xu ${ }^{1,2^{*}}$ and Ning Qin ${ }^{1,2^{*}}$

\begin{abstract}
Background: Ovarian follicle development plays an important role in determination of poultry egg production. The follicles at the various developmental stages possess their own distinct molecular genetic characteristics and have different biological roles in chicken ovary development and function. In the each stage, several genes of follicle-specific expression and biological pathways are involved in the vary-sized follicular development and physiological events. Identification of the pivotal genes and signaling pathways that control the follicular development is helpful for understanding their exact regulatory functions and molecular mechanisms underlying egg-laying traits of laying hens.

Results: The comparative mRNA transcriptomic analysis of ovarian follicles at three key developmental stages including slow growing white follicles (GWF), small yellow follicles (SYF) of recruitment into the hierarchy, and differentiated large yellow follicles (LYF), was accomplished in the layers with lower and higher egg production. Totally, 137, 447, and 229 of up-regulated differentially expressed genes (DEGs), and 99, 97, and 157 of down-regulated DEGs in the GWF, SYF and LYF follicles, including VIPR1, VIPR2, ADRB2, and HSD17B1 were identified, respectively. Moreover, NDUFAB1 and GABRA1 genes, two most promising candidates potentially associated with egg-laying performance were screened out from the 13 co-expressed DEGs in the GWF, SYF and LYF samples. We further investigated the biological effects of NDUFAB1 and GABRA1 on ovarian follicular development and found that NDUFAB1 promotes follicle development by stimulating granulosa cell (GC) proliferation and decreasing cell apoptosis, increases the expression of CCND1 and $\mathrm{BCL}-2$ but attenuates the expression of caspase-3, and facilitates steroidogenesis by enhancing the expression of STAR and CYP11A1. In contrast, GABRA1 inhibits GC proliferation and stimulates cell apoptosis, decreases the expression of CCND1, BCL-2, STAR, and CYP11A1 but elevates the expression of caspase-3. Furthermore, the three crucial signaling pathways such as PPAR signaling pathway, CAMP signaling pathway and neuroactive ligand-receptor interaction were significantly enriched, which may play essential roles in ovarian follicle growth, differentiation, follicle selection, and maturation.
\end{abstract}

\footnotetext{
*Correspondence: poultryxu@jlau.edu.cn; ningqin@jlau.edu.cn

${ }^{\dagger}$ Xue Sun and Xiaoxia Chen contributed equally to this work.

2 Department of Animal Genetics, Breeding and Reproduction,

College of Animal Science and Technology, Jilin Agricultural University,

Changchun 130118, China

Full list of author information is available at the end of the article
}

(C) The Author(s) 2021. Open Access This article is licensed under a Creative Commons Attribution 4.0 International License, which permits use, sharing, adaptation, distribution and reproduction in any medium or format, as long as you give appropriate credit to the original author(s) and the source, provide a link to the Creative Commons licence, and indicate if changes were made. The images or other third party material in this article are included in the article's Creative Commons licence, unless indicated otherwise in a credit line to the material. If material is not included in the article's Creative Commons licence and your intended use is not permitted by statutory regulation or exceeds the permitted use, you will need to obtain permission directly from the copyright holder. To view a copy of this licence, visit http://creativecommons.org/licenses/by/4.0/. The Creative Commons Public Domain Dedication waiver (http://creativeco mmons.org/publicdomain/zero/1.0/) applies to the data made available in this article, unless otherwise stated in a credit line to the data. 
Conclusions: The current study provided new molecular data for insight into the regulatory mechanism underlying ovarian follicle development associated with egg production in chicken.

Keywords: Ovarian follicle, Transcriptome, NDUFAB1 , GABRA1, Egg production

\section{Background}

Egg production initiates from the follicle prehierarchical and hierarchical development, maturation, and finally ovulates from the hen ovary, which is governed by the hypothalamic-pituitary-ovarian axis [1-3]. Ovarian follicle development plays a key role in the egg production capacity, which is characterized by a well-organized follicular hierarchy in high production egg-laying layers. In chickens with low egg-laying rates, e.g., the broiler breeder hen, follicular development is not well-organized, which leads to reduced productivity [1]. Generally, ovarian follicles can be categorized by size or/and according to color (white or yellow), into at least four types, including small white resting follicles (less than $2 \mathrm{~mm}$ diameter), slow growing white follicles (GWF, from $2 \mathrm{~mm}$ up to $6 \mathrm{~mm}$ diameter), small yellow follicles (SYF, 6 up to $8 \mathrm{~mm}$ ) of recruitment into the follicular hierarchy (at the stage of follicle selection), and large yellow follicles (LWF) at the differentiated preovulatory stage, being 9 to $12 \mathrm{~mm}$ in diameter and five to six hierarchical follicles of increased sizes (from F6 to F1) in hen ovary $[4,5]$. In the different phases of follicular development, many divergent biological processes affect oocyte growth, and proliferation and differentiation of granulosa and theca cells within the various-sized follicles [4, 6, 7]. Moreover, a plethora of ovarian paracrine and autocrine factors was involved in regulation of the follicle development and its function as well as the positive or negative controls through the endocrinal hormones from the hypothalamus and pituitary, including gonadotropin releasing hormone $(\mathrm{GNRH})$, gonadotropin inhibitory hormone (GNIH), and follicle stimulating hormone (FSH) [1, $2,8]$. Within the ovary, the most representative hormones and growth factors such as steroidogenic-related enzymes steroidogenic acute regulatory protein (STAR), hydroxysteroid (17beta) dehydrogenase 1 (HSD17B1) and cytochrome P450 side-chain cleavage (P450scc/ CYP11A1), intra-ovarian hormones progesterone (P4), estradiol (E2) and anti-müllerian hormone (AMH), cell proliferation or apoptosis-related factors Bcl-2, cyclin D1 (CCND1) and caspase-3 (CASP3), which have indispensable effects on follicular development, follicle selection or atresia, finally on their preovulatory development and ovulation, making the early developmental differences of ovarian follicles and egg production capacity in adult layers highly correlated, have been intensively investigated [9-13]. Undoubtedly, follicular size has a close relationship with its developmental biology, physiological function, and molecular regulation. It has been drawing so much attention to extensive exploration of the key genes and signaling pathways to be implicated in ovarian follicle development and potentially associated with egg production in chicken.

To intensively explore the molecular regulatory mechanisms underlying follicle development for better understanding egg production capacity, previous studies on transcriptome analyses of ovarian follicles, granulosa cells and theca cells of follicles as well as hypothalamus, pituitary gland and ovary, have revealed many genes involved in ovarian follicular development and follicle selection, which potentially correlate with the high capacity for egg production in chicken, goose, duck, and turkey. It has been reported that 20 differentially expressed transcripts (e.g., FTH1, TB, EEF1A1, TXN, $A N X A 2$, ING4, and $A C A D L$ ) associated with high rates of egg production in chicken ovarian follicles were screened out by cDNA microarray data analysis [14]. Several differentially expressed transcripts implicated in steroidogenesis (STAR, HSD3B, CYP11A1, and CYP19), paracrine signaling (PCSK6, KITL and WNT4) and transcription (FOXO3, FOXL2 and WT1) were identified by transcriptome analysis of the small ovarian follicles $0.5,1$, and $2 \mathrm{~mm}$ in diameter after oocyte removal in chicken, which may be important during early avian follicular development [15]. Transcriptomic analysis of single small yellow follicles demonstrated that Wnt4 takes part in the regulation of chicken follicle selection [16]. Transcriptomic analysis found 855 candidates differentially expressed between small yellow follicles (SYF, 6-8 $\mathrm{mm}$ in diameter) and F6 follicles in laying hens, including VLDLR1, WIF1, NGFR, AMH, BMP15, GDF6 and MMP13. They might play certain roles in chicken follicle selection [17]. Integrated transcriptomic analysis on chicken SYF differing in follicle stimulating hormone (FSH) receptor expression discovered 467 differentially expressed genes (DEGs). And sosondowah ankyrin repeat domain family member A (SOWAHA) gene was confirmed to affect the expression of genes involved in chicken follicle selection and to inhibit the proliferation of granulosa cells [18]. Moreover, RNA sequencing was used to analyze mRNAs and long noncoding RNAs (lncRNAs) from granulosa cells of SYFs from Jinghai Yellow chickens in exposure to red light and white light groups. One thousand one hundred eightytwo DEGs were identified and the integrated network 
analysis shown that several of them were involved in follicular development through steroid hormone synthesis, oocyte meiosis, and the PI3K-Akt signaling pathway [19].

Additionally, similar studies on transcriptome analysis of ovarian follicles were also reported in goose, duck and turkey. It was published that transcriptomic profiling identifies 688 DEGs in Huoyan goose ovaries (including the small and large yellow follicles) between the laying period and ceased period, in which the 12 validated genes, i.e., PGR, INSR, NPY1R, ESRRB, MEL1C, VIPR2, LHCGR, SCG2, GHR, STAR, HSD3B2, and CYP11A1, are mainly involved in the signal transduction pathways for reproduction regulation, such as steroid hormone biosynthesis, GnRH signaling pathways, oocyte meiosis, progesterone-mediated oocyte maturation, steroid biosynthesis, calcium signaling pathways, and G-protein coupled receptor signaling pathway [20]. Ren showed seven key DEGs, including EPOX, StAR, CYP17, 3 $\beta-H S D$, $C Y P 1 B 1, C Y P 19 A 1$, and $S R-B 1$, were related to Peking duck ovarian follicle development [21]. Moreover, transcriptome analysis of the granulosa layer of the largest follicle (F1) and fifth largest follicle (F5), theca interna layer of F5 follicle, and small white follicle samples from low and high egg producing turkey hens revealed 12,221 DEGs were identified, and among them, several of the most promising candidates and signaling pathways may be mainly involved in differential regulation of the hypothalamo-pituitary-thyroid axis, particularly thyroid hormone transporters and thyroid hormone receptors, and of estradiol signaling [22]. However, the pivotal genes and signaling pathways controlling the development of various-sized ovarian follicles in chicken, and their exact physiological roles and regulatory mechanisms in egg production remain largely unclear yet.

The Jilin Black (JB) chicken, an indigenous Chinese breed (dual-purpose type for egg and meat production), is characterized by high quality meat, but a low rate of egg production, low laying peak, and strong broodiness [23]. In contrast, the Lohmann Brown (LB) layer, a commercial egg-laying breed, is characterized as possessing a high rate of egg production, high laying peak, and great consistency in laying performance [24]. The differences in the egg production capacity between the JB and LB breeds may, therefore, serve as a proper basis for discovering potential key genes involved in egg production and for further investigating the molecular mechanism underlying formation of egg-laying traits in chicken.

To find the most potential genes and signaling pathways associated with egg production, comparative transcriptome analysis of ovarian GWF, SYF and LYF follicles between the JB and LB breeds was implemented. The present study aims to identify key functional genes implicated in ovarian follicular growth and development (including follicle selection) that directly contribute to egg-laying production. These results laid a molecular foundation for further elucidating the regulatory mechanisms of the promising genes in ovary development, and the pivotal signaling pathways in formation of chicken egg-laying traits.

\section{Results}

\section{Comparison of egg-laying production related traits between JB and LB hens}

Performance of egg-laying production related traits in $\mathrm{JB}$ and LB hens was evaluated, including age at first egg (AF), average body weight at 21 and 66 weeks of age (21BW and $66 \mathrm{BW})$, egg weight at 66 weeks of age (EW), hen-housed egg production $(\mathrm{HH})$ at 72 weeks of age, and egg production (total egg numbers per hen) rate at 21,30 , 43,57 and 66 weeks of age (21EN, 30EN, 43EN, 57EN and $66 \mathrm{EN})$. As shown in Table 1, the AF, which is the days of age when egg production rate per day reaches $50 \%$, was significantly earlier in LB than JB hens $(P<0.001)$. HH at 72 weeks of age was higher in LB than JB hens $(P<0.001)$. Moreover, egg production rates at $21,30,43,57$ and 66 weeks of age were also higher in LB when compared to JB hens $(P<0.001)$.

\section{Characteristics of RNA sequencing data}

Nine cDNA libraries of the GWF, SYF and LYF samples from JB and LB layers were constructed, respectively. In total, 822,883,832 sequence reads were obtained, and with an average of 45,430,781 clean reads each sample (Supplementary Table S1). On average, the clean data of high quality accounted for $99.09 \%$ of the sequences of raw reads, $85.59 \%$ of the clean reads were mapped to the reference genome of gallus gallus and $81.97 \%$ reads were mapped uniquely. The dynamic range of the expression

Table 1 Comparison of egg productions between JB and LB hens

\begin{tabular}{lllllllrrrr}
\hline Breed & AF & 21BW & 66BW & EW & HH & 21EN & 30EN & 43EN & 57EN & 66EN \\
\hline $\mathrm{LB}(n=720)$ & $141.2^{*}$ & $1.71 \pm 0.13$ & $1.98 \pm 0.45$ & $64.7 \pm 2.26$ & $289.6^{*}$ & $53.49^{*}$ & $93.82^{*}$ & $88.56^{*}$ & $83.75^{*}$ & $74.34^{*}$ \\
$\mathrm{~J}(n=458)$ & 206.5 & $1.78 \pm 0.19$ & $2.21 \pm 0.76$ & $62.9 \pm 4.48$ & 152.7 & 11.32 & 54.62 & 64.39 & 57.18 & 46.27 \\
\hline
\end{tabular}

$A F$ age at first egg (days), $B W$ average body weight (kg) at 21 and 66 weeks of age, $E W$ average egg weight (g) at 66 weeks of age, $H H$ average hen-housed egg production (egg numbers) at 72 weeks of age, EN average egg production rate (\%) at 21,30,43,57, and 66 weeks of age. The superscript asterisks

* indicates significant difference of the means at the level, $P<0.001$ 
values was estimated and exhibited as a box plot of logarithmic transformed FPKM values for each sample separately (Fig. 1A), and the FPKM density distribution is presented in Fig. 1B.

\section{Identification of differentially expressed genes and signaling pathway enrichment}

In this study, differentially expressed genes (DEGs) in the follicles of GWF, SYF and LYF between JB and LB hens were identified (The relevant datasets have been published by our group and are available at PRJNA669967 and PRJNA670553 in NCBI), respectively. In GWF follicles, 137 up-regulated and 99 down-regulated DEGs were revealed by comparison of JB with LB chickens (Fig. 2A; $\mid \log _{2}$ FoldChange $\mid>1, P<0.05$ ). Among them, the most important potential genes causing development of the undifferentiated follicles, which may be associated with egg production performance, were uncovered such as GABRA1, ADGRD1, VIPR2, APOD, BRINP1, PAK5, GPR65, RYR2, ZPBP, PIK3R1, EDIL3, TP53I3, BLK, POSTN, PERP1, HACD4, ZP1, WNT2B, CYP4F22, ADRB2, STARD4, CREB3L3, ACSBG2, GPER1, NDUFAB1, NCAM2, WISP1, MC2R, LOC424014, and RXRG (Table 2). Moreover, the significant top 20 signaling pathways were displayed (Fig. 2B), including PPAR signaling pathway, neuroactive ligand-receptor interaction, cAMP signaling pathway, fatty acid biosynthesis, cell adhesion molecules (CAMs), and AMPK signaling pathway.
In SYF follicles, 447 of up-regulated and 97 of downregulated DEGs were discovered in comparison of JB with LB chickens (Fig. 3A). Among them, the most interesting candidate DEGs to be implicated in follicle selection and differentiation, including GTSF1, P2RX1, GABRA1, GABRB2, NGF, ADGRD1, ADCY7, P2RX7, SRGN, SOX9, BCL2A1, GPR65, BCL2L14, ALDH1A1, BLK, GABRG1, METRN, P2RY12, CYP1C1, ADRB2, TENM2, GPR157, NDUFAB1, STMN3, PRLL, SOCS2, TLE4Z1, NCAM2, DTHD1, LOC424014, CYP2AB3, and $H S D 17 B 1$ were found (Table 3). Furthermore, the significant top 20 signaling pathways were identified (Fig. 3B). Among them, only two of the pathways, NF-kappa B signaling pathway, and CAMs, may be much closely linked with follicle development.

In LYF follicles, 229 of up-regulated and 157 of down-regulated DEGs were mined from JB and LB chickens (Fig. 4A). Of which, the most promising DEGs to be involved in follicle growth, differentiation and maturation such as $A P C D D 1, G A B R A 1$, TSHB, APOBEC2, PRLR, GHRHR-LR, NPY4R, BMPR2, TRH, HPGD, LEPR, CYP2D6, VIP, GREB1, SPEF2, PERP1, CRH, MAP3K9, RGS22, FABP7, SSTR2, RBP3, NDUFAB1, STMN3, PRLL, GAP43, NCAM2, LOC770492, CDKN1A, ID4, LOC424014, and CYP2AC2 were unveiled (Table 4). Moreover, the significant top 20 signaling pathways were obtained (Fig. 4B), which included retrograde endocannabinoid signaling, PPAR signaling pathway, neuroactive ligand-receptor
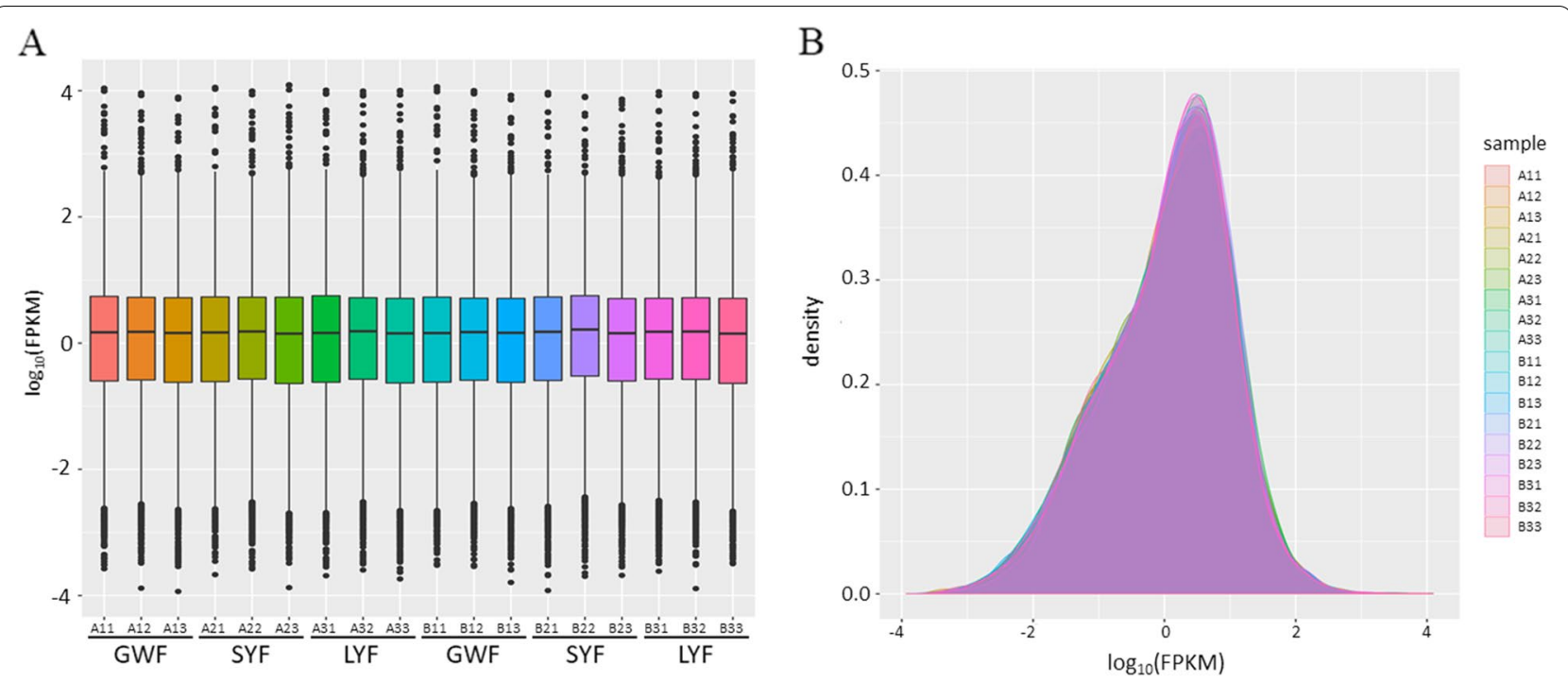

Fig. 1 FPKM distribution of transcript expression levels in the various-sized ovarian follicle samples. A Box plot of FPKM distribution with logarithmic values of FPKM on the vertical axis and different follicle samples on the horizontal axis. B Density plot of expression distribution with density values on the vertical axis and logarithmic values of FPKM on the horizontal axis. A1, A2, and A3, indicate GWF, SYF, and LYF follicle samples of LB hens, respectively; $B 1, B 2$, and $B 3$, indicate GWF, SYF, and LYF samples of JB hens, respectively 

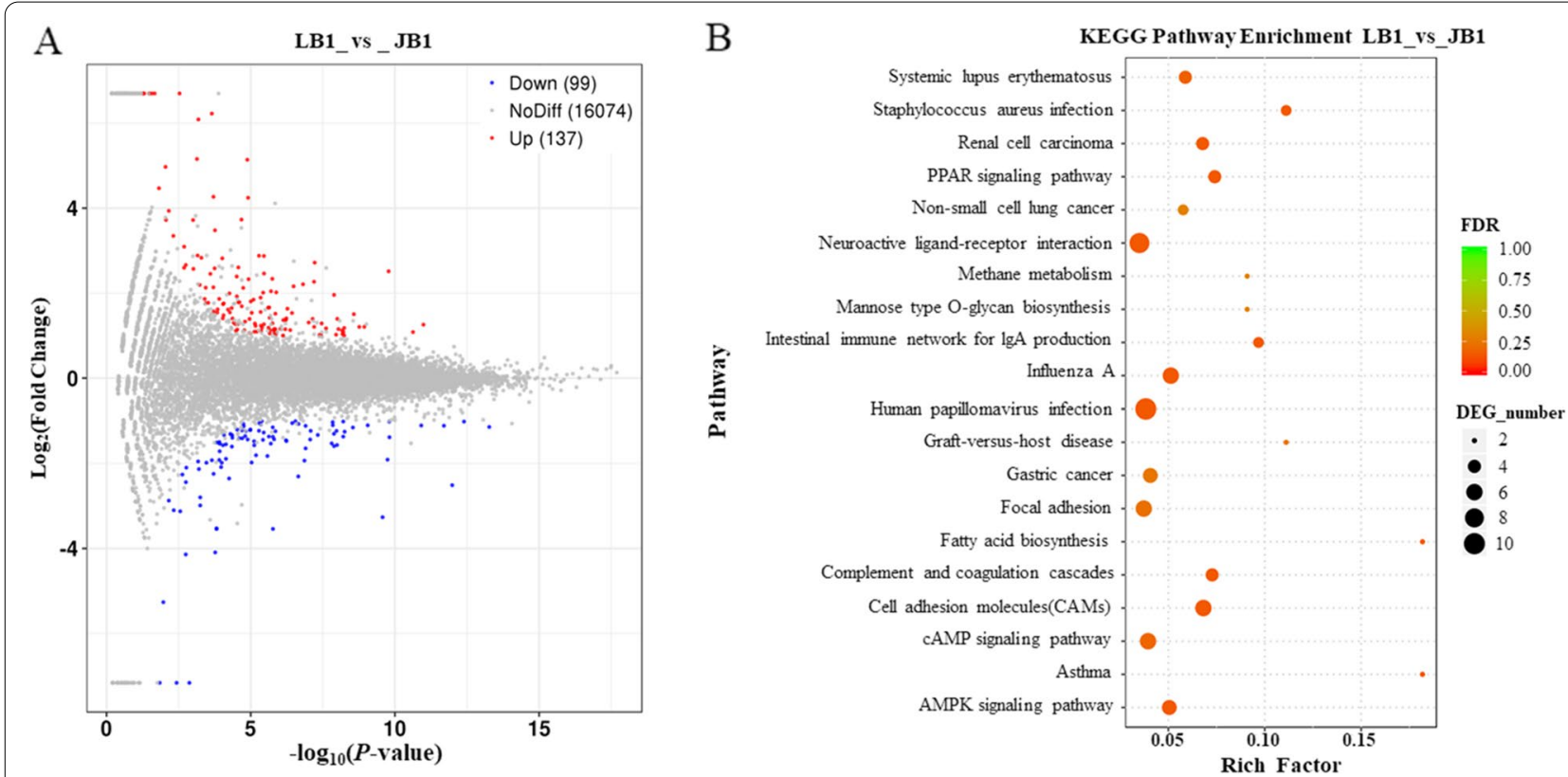

Fig. 2 Scatterplot of annotated differently expressed genes and enriched signaling pathways in GWF follicles between JB and LB chickens. A MA plot of differently expressed genes in GWF follicles between JB and LB samples. Y-axis: The logarithmic value ( $\log _{2}$ FoldChange) of the multiple of the difference in the expression level of a gene between two samples; $X$-axis: The negative pair value of the error detection rate ( $\left.-\log _{10} F D R\right)$. Red dots represent significantly up-regulated genes, blue dots indicate down-regulated genes, and grey dots imply non-differentially expressed genes ( $P$-value adjusted for multiple testing < 0.05). JB1, GWF follicle samples of JB hens; LB1, GWF samples of LB hens. B Bubble chart of top 20 signaling pathway enrichment with KEGG pathway on the vertical axis and rich impact values on the horizontal axis. Color indicates pathway with the $P$-values. Bubble size represents the ratio of DEG number to the total number of genes enriched on the pathway

interaction, mucin type O-glycan biosynthesis, JAKSTAT signaling pathway, circadian entrainment, CAMs, and cAMP signaling pathway.

To reveal the most important DEGs and signaling pathways potentially involved in follicle development and differentiation across the three developmental stages GWF, SYF and LYF, the NDUFAB1 and GABRA1 genes, two most promising candidates potentially associated with egg-laying performance were screened out from the 13 co-expressed DEGs in the GWF, SYF and LYF samples. The three crucial signaling pathways, including PPAR signaling pathway (ko 03320), cAMP signaling pathway (ko 04024), and neuroactive ligandreceptor interaction (ko 04080) were significantly enriched. Moreover, NDUFAB1 gene as a member of oxidative phosphorylation pathway (gga: 00190; Supplementary Fig. S1) was involved in the PPAR signaling pathway; while GABRA1 gene as a component of neuroactive ligand-receptor interaction pathway (gga: 04080; Supplementary Fig. S2) was implicated in the G protein-coupled receptor pathway (gga: 04030) which contains the FSH/FSHR signaling pathway, and in the cAMP signaling pathway.

\section{Validation of the selected DEGs by RT-qPCR}

Based on the analyses aforementioned, 20 representatives of most relevant DGEs, i.e., VIPR2, GABRA1, PERP1, ZP1, WISP1, MC2R, STARD4 and NDU$F A B 1$ that differentially expressed in GWF follicles, BCL2L14, LOC424014, ADRB2, GABRA1, PRLL, HSD17B1, NCAM2 and NDUFAB1 in SYF follicles, CYP2D6, CRH, GABRA1, GHRHR-LR, ID4, SSTR2, CDKN1A and NDUFAB1 in LYF follicles between JB and LB hens were selected for validation by RTqPCR. The results showed the significantly differential expression levels of the most transcripts determined by RT-qPCR analysis are consonant with the observation detected by RNA-seq (Fig. 5). While there are significant differences in the expression levels of the other genes, i.e., GABRA1, PERP1, BCL2L14, GHRHRLR, MC2R, STARD4, NDUFAB1, PRLL, and NCAM2, the observed expression trends were concordant with the RNA-seq results, confirming the transcriptome sequencing data are reliable, and can be further investigated for understanding the genetic mechanism of ovarian follicle development associated with egg production in chicken. 
Table 2 Characterization of partial DEGs in GWF follicles of JB and LB chickens

\begin{tabular}{|c|c|c|c|c|c|}
\hline Name & Description & Regulation & Chr. & $\log _{2} F C$ & $P$-value \\
\hline GABRA1 & gamma-aminobutyric acid type A receptor alpha1 subunit & up & 13 & 2.2084 & 4.8499E-07 \\
\hline ADGRD1 & adhesion G protein-coupled receptor D1 & up & 15 & 1.6618 & 0.0364 \\
\hline VIPR2 & vasoactive intestinal peptide receptor 2 & up & 2 & 2.2675 & 1.7403E-07 \\
\hline$A P O D$ & apolipoprotein D & up & 9 & 2.1226 & 3.8281E-05 \\
\hline BRINP1 & BMP/retinoic acid inducible neural specific 1 & up & 17 & 2.1930 & 0.0195 \\
\hline PAK5 & p21 (RAC1) activated kinase 5 & up & 3 & 1.0703 & 0.0047 \\
\hline GPR65 & G protein-coupled receptor 65 & up & 5 & 1.5475 & 0.0103 \\
\hline RYR2 & ryanodine receptor 2 & up & 3 & 2.3283 & 0.0048 \\
\hline$Z P B P$ & zona pellucida binding protein & up & 2 & 3.0925 & 0.0042 \\
\hline PIK3R1 & phosphoinositide-3-kinase regulatory subunit 1 & up & Z & 1.9585 & 0.0419 \\
\hline EDIL3 & EGF like repeats and discoidin domains 3 & up & Z & 2.0187 & 0.0052 \\
\hline TP53/3 & tumor protein p53 inducible protein 3 & up & 3 & 2.3365 & 0.0311 \\
\hline$B L K$ & BLK proto-oncogene, Src family tyrosine kinase & up & 3 & 1.2293 & 0.0085 \\
\hline POSTN & periostin & up & 1 & 1.0831 & 0.0325 \\
\hline PERP1 & PERP1, TP53 apoptosis effector & up & 3 & 5.1568 & 5.0997E-05 \\
\hline HACD4 & 3-hydroxyacyl-CoA dehydratase 4 & up & Z & 2.8745 & 0.0171 \\
\hline ZP1 & zona pellucida glycoprotein 1 & up & 5 & 1.2576 & 0.0337 \\
\hline WNT2B & Wnt family member 2B & up & 26 & 2.5831 & 0.0003 \\
\hline CYP4F22 & Cytochrome P450 family 4 subfamily member 22 & up & 30 & 1.5370 & 0.0018 \\
\hline ADRB2 & adrenoceptor beta 2 & up & 13 & 1.5427 & 0.0292 \\
\hline STARD4 & StAR related lipid transfer domain containing 4 & down & Z & -1.3823 & 3.0970E-09 \\
\hline CREB3L3 & CAMP responsive element binding protein 3 like 3 & down & 28 & -1.8905 & 0.0031 \\
\hline ACSBG2 & acyl-CoA synthetase bubblegum family member 2 & down & 28 & -1.0163 & $1.6471 \mathrm{E}-05$ \\
\hline GPER1 & G protein-coupled estrogen receptor 1 & down & 14 & -1.9229 & 0.0171 \\
\hline NDUFAB1 & NADH: ubiquinone oxidoreductase subunit AB1 & down & 14 & -1.2524 & 0.0062 \\
\hline NCAM2 & neural cell adhesion molecule 2 & down & 1 & -1.9101 & 0.0049 \\
\hline WISP1 & WNT1 inducible signaling pathway protein 1 & down & 2 & -1.2337 & 4.4686E-06 \\
\hline$M C 2 R$ & melanocortin 2 receptor & down & 2 & -2.7876 & 4.9574E-05 \\
\hline LOC424014 & putative methyltransferase DDB_G0268948 & down & 7 & -3.5398 & 5.0597E-20 \\
\hline$R X R G$ & retinoid $X$ receptor gamma & down & 8 & -1.4435 & 0.0017 \\
\hline
\end{tabular}

\section{Confirmation of the roles of NDUFAB1 and GABRA1 genes in ovarian follicle development}

To further confirm the exact roles of NDUFAB1 and $G A B R A 1$ genes in ovarian follicle development, silence of the genes was performed by infection of the shRNA lentivirus in the GCs from 6 to $8 \mathrm{~mm}$ follicles of hen ovaries, respectively. The result demonstrated that in the NDUFAB1 silencing GCs, expression levels of STAR, CYP11A1, CCND1, and BCL-2 proteins as well as all of their transcripts were significantly downregulated $(P<0.01$, Fig. 6; Supplementary Fig. S3), but the expression Caspase- 3 and its transcript were remarkably upregulated $(P<0.001)$. Simultaneously, cell proliferation ratio of the GCs was notably decreased as compared to the negative control $(P<0.05$, Fig. 7$)$, whereas cell apoptosis rate was markedly increased
$(P<0.001)$. It was suggested that NDUFAB1 promotes follicle development by stimulating GC proliferation and decreasing cell apoptosis, increases the expression of CCND1 and BCL-2 but attenuates the expression of caspase-3, and facilitates steroidogenesis by enhancing the expression of STAR and CYP11A1.

For GABRA1 silence of GCs, the expression levels of STAR, CYP11A1, CCND1, and BCL-2 transcripts and their proteins were notably elevated $(P<0.01$, Fig. 8; Supplementary Fig. S4). Oppositely, the expression $C A S P 3$ transcript and its protein were significantly reduced $(P<0.001)$. Furthermore, cell proliferation ratio of the GCs was remarkably enhanced as compared to the negative control $(P<0.01$, Fig. 9), conversely, cell apoptosis rate was sharply decreased $(P<0.001)$. It was proposed that GABRA1 inhibits GC proliferation and 

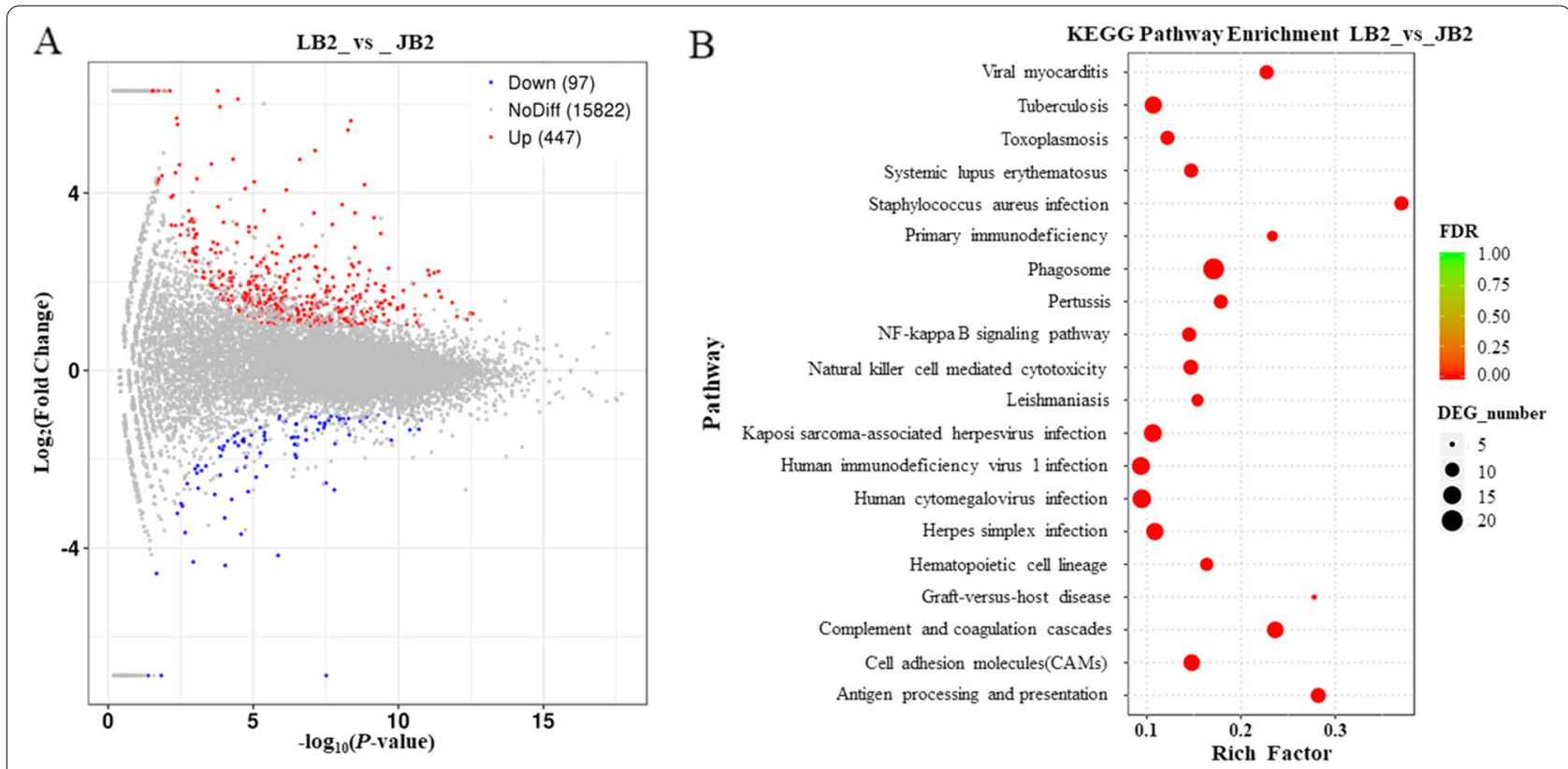

Fig. 3 Scatter plot of annotated differently expressed genes and enriched signaling pathways in SYF follicles between JB and LB chickens. A MA plot of differently expressed genes in SYF follicles between JB and LB samples. JB2, SYF follicle samples of JB hens; LB2, SYF samples of LB hens. B Bubble chart of top 20 of KEGG pathway enrichment

increases cell apoptosis, decreases the expression of CCND1, BCL-2, STAR, and CYP11A1 but elevates the expression of caspase- 3 .

\section{Discussion}

Ovary is an important reproductive organ in adult poultry, which contains many various-sized follicles corresponding to the different follicular developmental stages, including the small white follicle resting (months or years) stage $(<2 \mathrm{~mm})$, the slow growing undifferentiated prehierarchical stage (white, $2-6 \mathrm{~mm}$ ), the stage of follicle selection (small, yellow; $6-8 \mathrm{~mm}$ ), and the final differentiated hierarchy (large, yellow) stage $[1,4,5]$. The follicles mainly composed of oocytes, granulosa cell layers (GCs) and theca cell layers, are the major compartments which enable the ovary to execute its dual function of gametogenesis and steroidogenesis in chicken [25]; its development is a highly intricate and coordinated hierarchical process involving a multitude of biological events controlled by reproductive hormones in the ovary $[8,26$, 27]. Undoubtedly, the follicles at the various developmental stages possess their own distinct molecular genetic characteristics and play different roles in contributing to ovary growth and development. Particularly, genetic regulation of 6-8 $\mathrm{mm}$ diameter follicles is generally involved in follicle selection $[2,28,29]$ and may possess an exclusive influence on hierarchy of undifferentiated prehierarchical follicles. However, the major genes controlling the follicle development at each stage and their exact physiological mechanisms that regulate follicular growth and order of the ovarian follicle hierarchy remain largely unknown.

To mine the key genes implicated in follicular development at the stages of follicle selection, before and after the selection, in this study, transcriptome analysis of the GWF, SYF and LYF follicles was implemented between the JB and LB chicken breeds. To our knowledge, this is one of the few studies to reveal potential pivotal genes of involvement in hen ovarian follicles at the developmental stages immediately before and after follicle selection, which may be associated with high and low rates of egg production. Firstly, in the GWF follicles of this study, the JB hens with low egg production showed higher mRNA levels of VIPR2, GABRA1, PERP1, and ZP1, and lower mRNA levels of WISP1, MC2R, STARD4, and NDU$F A B 1$ genes, in which the most representative gene VIPR2 is also named pituitary adenylate cyclase-activating polypeptide (PACAP) receptor (VPAC2), encoding the VPAC2/vasoactive intestinal peptide (VIP) receptor (VIPR2) belonging to the VIP/PACAP type II receptors, including VPAC1/VIPR1 and VPAC2/VIPR2 [30, 31]. Previous studies have proved that PACAP, a bioactive peptide transiently expressed in preovulatory follicles, stimulates various ovarian functions, such as intracellular cyclic AMP (cAMP) accumulation, plasminogen activator production, and inhibits GC apoptosis by interacting 
Table 3 Characterization of partial DEGs in SYF follicles of JB and LB chickens

\begin{tabular}{|c|c|c|c|c|c|}
\hline Name & Description & Regulation & Chr. & $\log _{2} F C$ & $P$-value \\
\hline GTSF1 & gametocyte specific factor 1 & up & 27 & 1.0872 & 0.0009 \\
\hline$P 2 R \times 1$ & purinergic receptor $\mathrm{P} 2 \mathrm{X} 1$ & up & 19 & 1.7095 & 0.0383 \\
\hline GABRA1 & gamma-aminobutyric acid type A receptor alpha 1 subunit & up & 13 & 1.7586 & $1.2116 \mathrm{E}-05$ \\
\hline GABRB2 & gamma-aminobutyric acid type A receptor beta2 subunit & up & 13 & 1.5317 & 0.0028 \\
\hline NGF & nerve growth factor & up & 26 & 1.7033 & 0.0481 \\
\hline ADGRD1 & adhesion G protein-coupled receptor D1 & up & 15 & 2.6266 & 0.0187 \\
\hline$A D C Y 7$ & adenylate cyclase 7 & up & 11 & 1.0016 & 0.0289 \\
\hline$P 2 R X 7$ & purinergic receptor $\mathrm{P} 2 \mathrm{X} 7$ & up & 15 & 1.6691 & 4.0602E-05 \\
\hline SRGN & serglycin & up & 6 & 1.9189 & 0.0205 \\
\hline sox9 & SRY (sex determining region Y)-box 9 & up & 18 & 1.5868 & 0.0084 \\
\hline$B C L 2 A 1$ & $B C L 2$ related protein $A 1$ & up & 10 & 1.6446 & 0.0340 \\
\hline GPR65 & G protein-coupled receptor 65 & up & 5 & 1.3260 & 0.0187 \\
\hline$B C L 2 L 14$ & BCL2 like 14 & up & 1 & 4.3212 & $1.7558 \mathrm{E}-05$ \\
\hline$A L D H 1 A 1$ & aldehyde dehydrogenase 1 family member A1 & up & Z & 2.3347 & 0.0099 \\
\hline$B L K$ & BLK proto-oncogene, Src family tyrosine kinase & up & 3 & 1.3837 & 0.0034 \\
\hline GABRG1 & gamma-aminobutyric acid type A receptor gamma1subunit & up & 4 & 1.8060 & 0.0005 \\
\hline METRN & meteorin, glial cell differentiation regulator & up & 14 & 1.0096 & 0.0087 \\
\hline P2RY12 & purinergic receptor $\mathrm{P} 2 \mathrm{Y} 12$ & up & 9 & 1.5714 & 0.0255 \\
\hline LOC424014 & putative methyltransferase DDB_G0268948 & up & 7 & $2.0292 \mathrm{E}-06$ & 2.3334 \\
\hline CYP1C1 & cytochrome P450 family 1 subfamily C polypeptide 1 & up & 5 & 2.8918 & 0.0053 \\
\hline$A D R B 2$ & adrenoceptor beta 2 & up & 13 & 1.2618 & 0.0388 \\
\hline TENM2 & teneurin transmembrane protein 2 & down & 13 & -1.4428 & $1.0434 \mathrm{E}-05$ \\
\hline GPR157 & G protein-coupled receptor 157 & down & 21 & -1.14768 & 0.0104 \\
\hline NDUFAB1 & NADH: ubiquinone oxidoreductase subunit AB1 & down & 14 & -1.0438 & 0.0180 \\
\hline STMN3 & stathmin 3 & down & 20 & -1.5957 & 0.0110 \\
\hline$P R L L$ & prolactin-like protein & down & 1 & -1.5757 & 0.0130 \\
\hline SOCS2 & suppressor of cytokine signaling 2 & down & 1 & -1.2871 & 0.0062 \\
\hline TLE4Z1 & transducin like enhancer of split 4-Z1 & down & Z & -1.0419 & 0.0164 \\
\hline NCAM2 & neural cell adhesion molecule 2 & down & 1 & -6.8712 & 0.0013 \\
\hline DTHD1 & death domain containing 1 & down & 4 & -2.1469 & $3.5106 \mathrm{E}-05$ \\
\hline$C Y P 2 A B 3$ & cytochrome P450, family 2, subfamily AB, polypeptide 3 & down & 9 & -1.6150 & 0.0142 \\
\hline HSD17B1 & Hydroxyl steroid (17-beta) dehydrogenase 1 & down & 27 & -1.6963 & 0.0243 \\
\hline
\end{tabular}

with its receptors, PACAP type I receptor (PAC1) and the type II receptors in rat [32-34]. Moreover, PACAP stimulates oocyte growth but block its maturation in early follicles by acting directly on the oocyte via PAC1 and VPAC2 receptors, whose expression is dominant in growth phase [35]. The participation of VIP in ovarian steroids production was confirmed to induce polycystic ovary $[36,37]$. Therefore, it was proposed that the higher expression of VIPR2 transcript in GWF developmental stage may be relevant to broodiness and lower egg-laying trait of JB breed by blocking follicle growth and maturation in ovarian follicle development.

In this study, transcriptomic analysis of SYF follicles revealed higher mRNA levels of BCL2L14, LOC424014, $A D R B 2$, and GABRA1, and lower mRNA levels of PRLL,
HSD17B1, NCAM2, and NDUFAB1 genes in the JB hens as compared with LB hens, in which the most representative genes, $A D R B 2$ and $H S D 17 B 1$, have been intensively studied in ovarian functions $[38,39]$. The $\beta 2$ adrenergic receptor (ADRB2) encoded by $A D R B 2$ gene was mainly expressed in the GCs and Theca cells (TCs) of ovarian follicles and regulated the levels of cAMP and steroid production through activation of ADRB2/cAMP/protein kinase A (PKA) signaling pathway and/or ADRB2/ cAMP/protein, phospholipase C (PLC)/protein kinase C (PKC)/cAMP response element-binding protein (CREB) signaling cascade [40-42]. However, the excessive ovarian steroidal response to gonadotropins and beta-adrenergic stimulation enhanced polycystic ovary syndrome (PCOS), an endocrine disorder characterized 

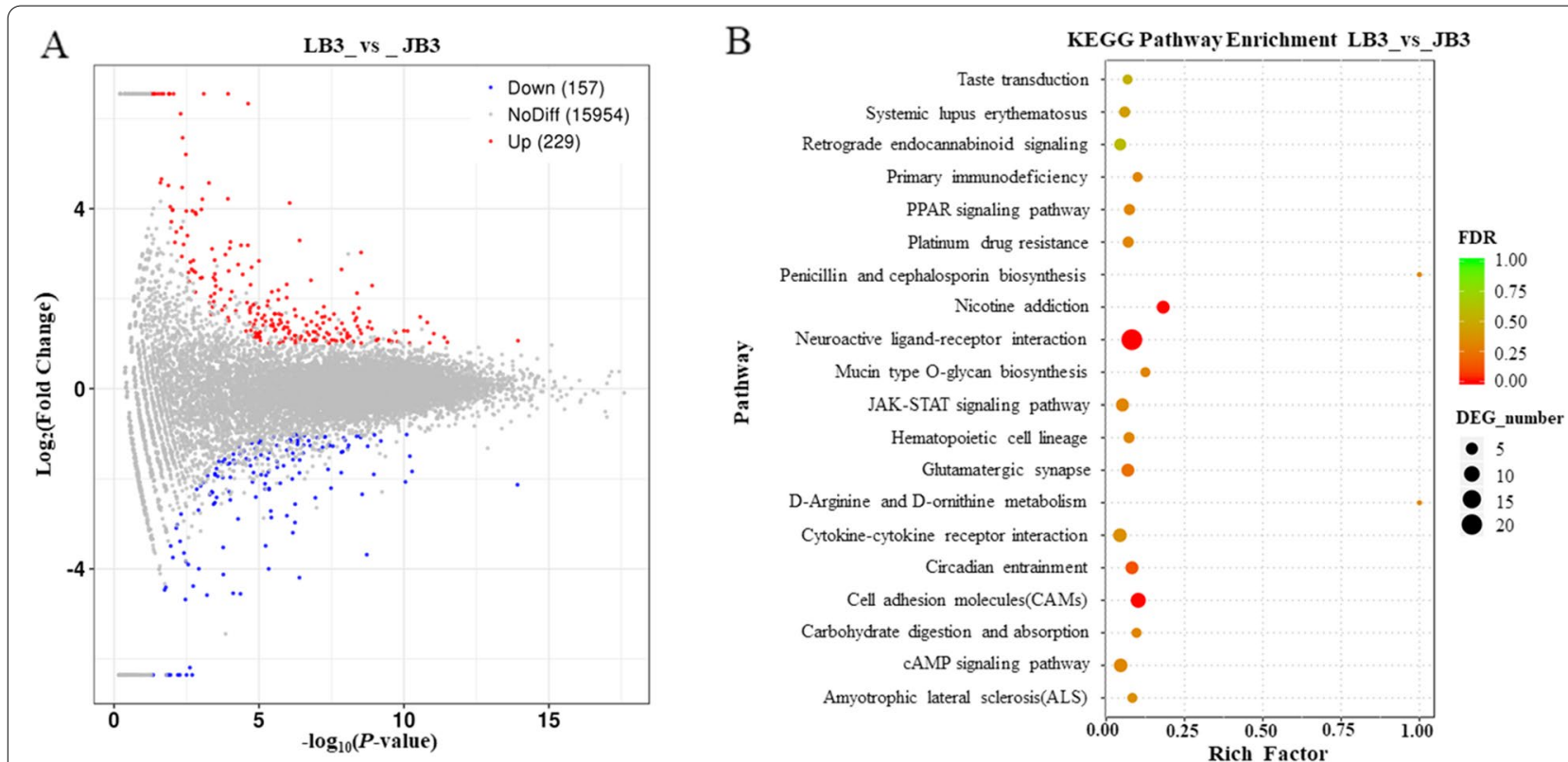

Fig. 4 Scatter plot of annotated differently expressed genes and enriched signaling pathways in LYF follicles between JB and LB chickens. A MA plot of differently expressed genes in GWF follicles between JB and LB samples. JB3, LYF follicle samples of JB hens; LB3, LYF samples of LB hens. B Bubble chart of top 20 of KEGG pathway enrichment

by anovulation, hyperandrogenism and polycystic ovaries $[36,37,43,44]$. The much abundant expression levels of $A D R B 2$ gene may induce layer broodiness by activation of adenylate cyclase through the action of $\mathrm{G}$ proteins and stimulate anovulation [37, 43].

The hydroxysteroid (17beta) dehydrogenase type 1 (HSD17B1) is a steroidogenic enzyme encoded by $H S D 17 B 1$ gene, to efficiently catalyze reversible interconversion of a low-active precursor estrogen estrone (E1) to the highly active E2 that is necessary for normal ovary development $[13,45]$. It is the major isozyme in the granulosa cells of the ovary and has a central role in regulating the circulating estradiol concentration as well as its local production in estrogen target cells, locally promotes development, differentiation, and maturation of the follicle [46-48]. Nevertheless, inhibition of HSD17B1 impairs the synthesis of $17 \beta$-estradiol, and attenuates action of the estradiol $[47,49]$, which can directly block ovarian follicle development. Furthermore, HSD17B1 plays a crucial role in controlling cell proliferation and in the regulation of the growth and function of organs [50]. It was suggested that the lower expression levels of $H S D 17 B 1$ transcript in SYF follicles of JB hens may affect ovarian dominant follicle selection and follicle growth and function by repressing $17 \beta$-estradiol production and follicle cell proliferation, and finally lead to a low egg production.

Transcriptomic analysis of LYF follicles revealed higher mRNA levels of CYP2D6, CRH, GABRA1, and GHRHR$L R$, and lower mRNA levels of ID4, SSTR2, CDKN1A and NDUFAB1 genes in the JB than in the LB layers. Among them, the most representative gene GHRHR$L R$, also named VIPR1, its encoding product VIPR1 was mainly expressed in granulosa cells and residual ovarian tissue [51]. PACAP may promote oocyte maturation in the maturation phase via VPAC1-R on the follicle cells, whose expression surges in full-grown follicles prior to maturation and is consistently high in the follicles undergoing final maturation [35]. Moreover, the genetic polymorphisms of VIP and VIPR1 genes were associated with chicken broodiness and egg production [52, 53]. It was intimated that the higher expression levels of VIPR1 transcript in LYF follicles of JB hens may inhibit ovarian follicle growth, differentiation and maturation, and contribute to the lower egg production.

Interestingly, the significantly up-regulated GABRA1 mRNA and down-regulated NDUFAB1 mRNA of the GWF, SYF and LYF follicles were co-expressed differentially in JB hen ovaries when compared with LB hen. Previous studies have reported that GABRA1 gene encodes $\gamma$-aminobutyric acid type A receptor $\alpha 1$ subunit (GABRA1) is one subtype of the neurotransmitter $\gamma$-aminobutyric acid (GABA) activating $\mathrm{GABA}_{\mathrm{A}}$ receptors that act as the components of the gammaaminobutyric acid signaling pathway $[54,55]$. The heteropentameric receptors are formed from an array of subunits $(\alpha 1-6, \beta 1-3, \gamma 1-3, \delta, \varepsilon, \pi, \theta$ and $\rho 1-3)$, producing receptors with diverse functional and pharmacological properties [56-58]. The $\mathrm{GABA}_{\mathrm{A}}$ receptors are 
Table 4 Characterization of partial DEGs in LYF follicles of JB and LB chickens

\begin{tabular}{|c|c|c|c|c|c|}
\hline Name & Description & Regulation & Chr. & $\log _{2} F C$ & $P$-value \\
\hline$A P C D D 1$ & APC down-regulated 1 & up & 2 & 1.4852 & 0.0052 \\
\hline GABRA1 & gamma-aminobutyric acid type A receptor alpha 1 subunit & up & 13 & 1.8192 & 1.0197E-06 \\
\hline TSHB & thyroid stimulating hormone beta & up & 26 & 2.8128 & 0.0113 \\
\hline$A P O B E C 2$ & apolipoprotein B mRNA editing enzyme catalytic subunit 2 & up & 26 & 1.0499 & 0.0021 \\
\hline$P R L R$ & prolactin receptor & up & Z & 2.1874 & 8.7121E-07 \\
\hline GHRHR-LR & growth-hormone releasing hormone-like peptide receptor & up & 2 & 3.7088 & 0.0236 \\
\hline NPY4R & neuropeptide $Y$ receptor $Y 4$ & up & 6 & 4.0431 & 0.0204 \\
\hline BMPR2 & bone morphogenetic protein receptor type 2 & up & 7 & 1.0301 & 0.0253 \\
\hline $\mathrm{TRH}$ & thyrotropin releasing hormone & up & 12 & 1.6478 & 0.0474 \\
\hline$H P G D$ & 15-hydroxyprostaglandin dehydrogenase & up & 4 & 1.4899 & 0.0168 \\
\hline$L E P R$ & leptin receptor & up & 8 & 1.1635 & 0.0002 \\
\hline CYP2D6 & cytochrome P450 family 2 subfamily D member 6 & up & 1 & 1.5767 & 0.0030 \\
\hline VIP & vasoactive intestinal peptide & up & 3 & 2.4115 & 0.0174 \\
\hline GREB1 & growth regulating estrogen receptor binding 1 & up & 3 & 1.0473 & 0.0006 \\
\hline SPEF2 & sperm flagellar 2 & up & Z & 1.3693 & 0.0018 \\
\hline PERP1 & TP53 apoptosis effector & up & 3 & 4.2193 & $6.2651 \mathrm{E}-06$ \\
\hline $\mathrm{CRH}$ & corticotropin releasing hormone & up & 2 & 4.5714 & 1.4447E-07 \\
\hline MAP3K9 & mitogen-activated protein kinase kinase kinase 9 & up & 5 & 1.1066 & 0.0074 \\
\hline RGS22 & regulator of $G$ protein signaling 22 & up & 2 & 1.1938 & 0.0013 \\
\hline FABP7 & fatty acid binding protein 7 & up & 3 & 1.0730 & 0.0004 \\
\hline SSTR2 & somatostatin receptor 2 & down & 18 & -1.6523 & 0.0161 \\
\hline RBP3 & retinol binding protein 3 & down & 6 & -2.8177 & 0.0003 \\
\hline NDUFAB1 & NADH: ubiquinone oxidoreductase subunit AB1 & down & 14 & -2.2040 & $1.9938 \mathrm{E}-10$ \\
\hline STMN3 & stathmin 3 & down & 20 & -1.2830 & 0.0434 \\
\hline$P R L L$ & prolactin-like protein & down & 1 & -1.4488 & 0.0323 \\
\hline GAP43 & growth associated protein 43 & down & 1 & -2.7814 & 0.0468 \\
\hline NCAM2 & neural cell adhesion molecule 2 & down & 1 & -2.0656 & 0.0087 \\
\hline LOC770492 & ras-related and estrogen-regulated growth inhibitor-like & down & 5 & -1.0108 & 0.0180 \\
\hline CDKN1A & cyclin dependent kinase inhibitor $1 \mathrm{~A}$ & down & 26 & -1.0877 & 0.0151 \\
\hline 104 & inhibitor of DNA binding 4, HLH protein & down & 2 & -1.2727 & $6.0076 \mathrm{E}-05$ \\
\hline LOC424014 & putative methyltransferase DDB_G0268948 & down & 7 & -1.5789 & $6.3016 \mathrm{E}-05$ \\
\hline CYP2AC2 & cytochrome P450, family 2, subfamily AC, polypeptide 2 & down & 3 & -3.8372 & 0.0022 \\
\hline
\end{tabular}

vital for controlling neuronal excitability and can display significant levels of constitutive activity that contributes to tonic inhibition [58]. It has been established that the progesterone metabolite allopregnanolone, a potent modulator of the $\mathrm{GABA}_{\mathrm{A}}$ receptor, is sedative in high concentrations but may precipitate paradoxical adverse effects on mood at levels corresponding to luteal phase concentrations in susceptible women [59]. It indicated that $\mathrm{GABA}_{\mathrm{A}}$ receptors may be loosely linked to reproductive performance in chicken. Furthermore, And the configuration of GABRA1 proves the receptor's vital role in apoptosis regulations, mitochondrial function, inhibitory effects of different neurotransmitters, and synaptic plasticity by interaction with neuroactive steroids such as androstane and progesterone derivatives [57, 60].
Moreover, another studies on NDUFAB1 gene demonstrated that the NDUFAB1 gene encodes the acyl carrier protein $(\mathrm{ACP}), \mathrm{NDUFAB1}$ subunit of mitochondrial complex I (NADH: ubiquinone oxidoreductase), which is involved in cytosolic and mitochondrial fatty acid synthesis pathways [61]. ACP molecule is a universal and highly conserved carrier of acyl intermediates during fatty acid synthesis [62], exists either in the cytosol as a separate domain within a large multifunctional fatty acid synthase polyprotein (type I FAS) or in mitochondria as a discrete entity ACP of the bacterial type II FAS $[63,64]$. However, the exact roles of GABRA1 and the NDUFAB1 in ovarian follicular function remain unclear in chicken.

To further confirm the roles of GABRA1 and NDU$F A B 1$ genes in ovarian follicle development, silencing 


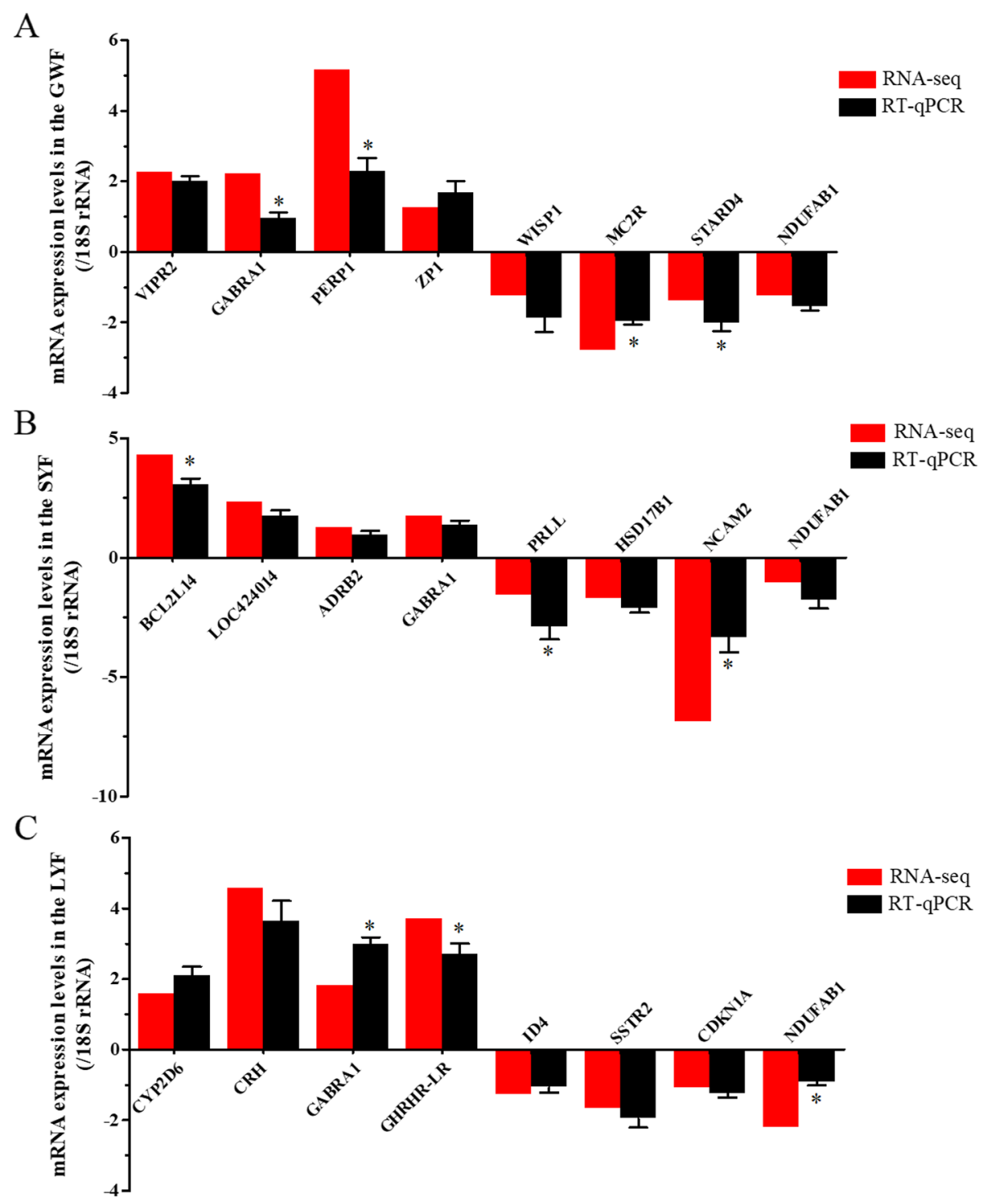

Fig. 5 Evaluation and comparison of mRNA expression levels $\left(\log _{2} \mathrm{FC}\right)$ of 20 candidate genes when analyzed by RNA Seq and quantitative RT-qPCR. A The candidates in the differentially expressed in GWF follicles between JB and LB hens. B The candidates in SYF follicles. C The candidates in LYF follicles. The relative expression level of each gene was quantified by the $2^{-\triangle \Delta C T}$ method and 185 rRNA was used as the internal control for normalization of the results

GABRA1 and NDUFAB1 genes were conducted in the GCs of SYF, respectively. The result showed that expression levels of the steroidogenic-related genes, both $S T A R$ and CYP11A1, were remarkably enhanced when silencing GABRA1 was implemented in the GCs. As known, the STAR and P450scc were two key enzymes in regulation of P4 synthesis and secretion within the GCs. In which, STAR functions to transport cholesterol to the inner membrane of mitochondria from the outer membrane [65], then P450scc catalyzes transformation of cholesterol to pregnenolone, a P4 precursor [66]. It is well shown that as follicle was recruited into the follicular hierarchy (follicle selection), the granulosa cells initiate differentiation, and accompanied by the $\mathrm{P} 4$ synthesis and secretion $[67,68]$. P4 is required for growth and ovulation of preovulatory follicles, exerts a stage-dependent role in ovarian follicle development [69]. However, high level of progesterone markedly inhibited ovulation of preovulatory follicles, and generally delayed oviposition by negative feedback fashion on the gonadotroph in hens $[69,70]$. In this study, the higher expressions of GABRA1 can decrease P4 production by inhibiting STAR 

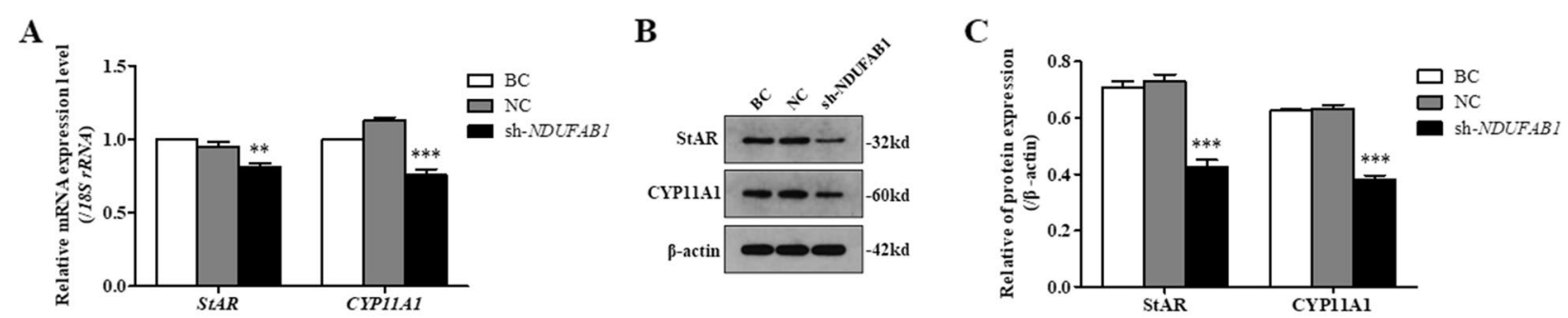

D

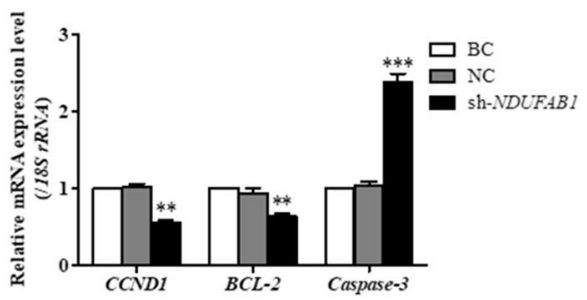

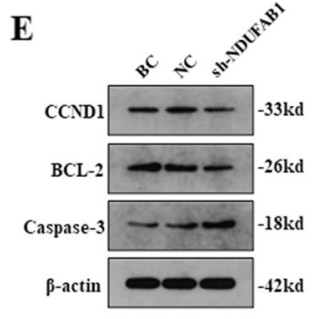

$\mathbf{F}$

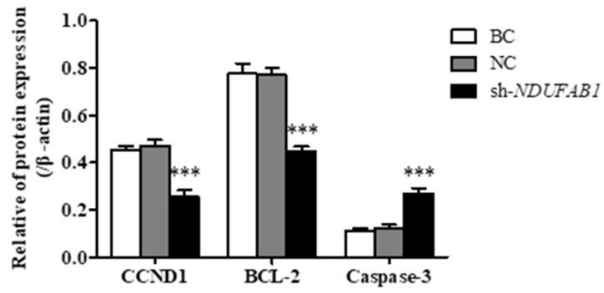

Fig. 6 Silence of NDUFAB1 in the GCs. sh-NDUFAB1, GCs being transfected with NDUFAB1-specific shRNA; NC, scrambled shRNA (negative control); BC, no shRNA as a vehicle (blank control). A The STAR and CYP11A1 mRNA expression in the GCs was analyzed using RT-qPCR. B, C Expression of STAR and CYP11A1 proteins in the GCS with or without interference using the shRNA was analyzed by western blotting; $\beta$-actin was used as a loading control. D The CCND1, BCL-2 and caspase-3 (CASP3) mRNA expression in the GCs was analyzed using RT-GPCR. E, F Expression of CCND1, $\mathrm{BCL}-2$ and caspase-3 proteins in the GCs with or without interference using the shRNA was analyzed by western blotting

and CYP11A1 expression level. But the much lower P4 level or P4 absence also suppressed folliculogenesis and ovulation [71, 72]. Concurrently, expression levels of cell proliferation related genes $B C L-2$ and $C C N D 1$ genes were significantly elevated in the GCs, whereas the expression of CASP3 gene was notably decreased. Furthermore, the cell proliferation ratio of the GCs was remarkably enhanced as compared to the negative control; conversely, cell apoptosis rate was sharply decreased as GABRA1 expression was silenced. Although the exact roles and regulatory mechanism of GABRA1 and the GABAR in ovarian follicular function remain unclear in chicken, a study reported the inhibitory effect of xanthohumol on evoked glutamate release was antagonized by suppressing the GABAR/ $/ \mathrm{Ca}^{2+}$-calmodulin/AC/cAMP/ PKA cascade in rat hippocampus [73]. Moreover, the AC/cAMP/PKA pathway was involved in granulosa cell proliferation and differentiation of ovarian follicles in hen $[74,75]$. Our result showed GABRA1 gene plays an inhibitory role in ovarian follicle development, follicle selection and differentiation by suppressing steroidogenesis, GC proliferation and stimulating cell apoptosis of SYF.

As aforementioned, it was found that the expression NDUFAB1 mRNA in the ovarian follicles of three developmental stages was down-regulated in the JB hens. Previous studies corroborated that NDUFAB1 is linked directly to mitochondrial ATP production, indirectly to potential reactive oxygen species generation [76], and reduced mitochondrial ATP production directly resulted in increased cell apoptosis [77]. Moreover, down-regulation of mitochondrial ACP expression in HEK293T cells has brought about a slowing of cell growth rate or a high level of cell death [78]. It was consistent with our results that the GC proliferation ratio was notably decreased; moreover, cell apoptosis rate was markedly increased when NDUFAB1 expression was silenced. Simultaneously, it was accompanied by the significant downregulation of STAR, CYP11A1, CCND1, and BCL-2 expression, and remarkably upregulated Caspase- 3 expression. It confirmed that NDUFAB1 has a positive regulation in ovary follicular growth and differentiation at the developmental stage of follicle selection by enhancing steroidogenesis, GC proliferation and decreasing cell apoptosis. Furthermore, this study has shown the expression levels of NDUFAB1 mRNA across the three developmental stages of GWF, SYF and LYF in ovary development keeps lower in JB hens than in LB layers, but the higher expression of GABRA1 transcripts. Accordingly, it was concluded both NDUFAB1 and GABRA1 genes were strongly associated with egg-laying production of hens.

Additionally, in this study three crucial signaling pathways including PPAR signaling pathway, cAMP signaling pathway, and neuroactive ligand-receptor interaction were screened out. Among them, the cAMP signaling pathway was not only involved in the neuroactive ligandreceptor interaction such as the $\mathrm{GABAR} / \mathrm{Ca}^{2+}$-calmodulin/AC/cAMP/PKA cascade of the GABAergic synapse pathway $[54,73]$, it also provokes a variety of processes 


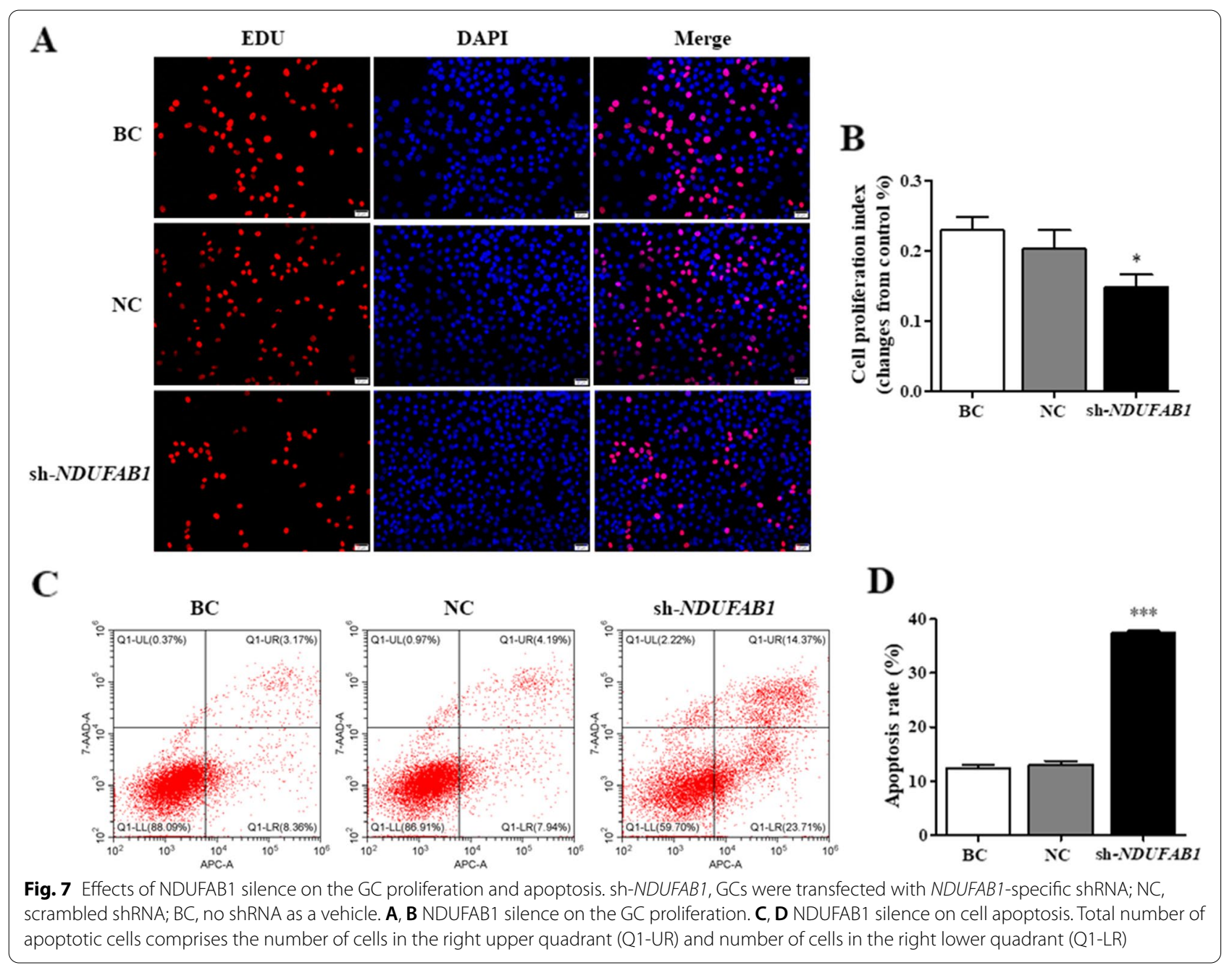

required for ovarian follicle growth, selection, differentiation, and maturation [74, 79]. As is well known, FSH is essential for reproductive system including steroidogenesis, folliculogenesis, and follicular maturation by interaction with FSH receptor (FSHR) in an endocrine dependent manner [80, 81]. FSHR, a member of the superfamily of G-protein-coupled receptors, is exclusively expressed on granulosa cells of ovarian follicles and mediates FSH signal transduction through cAMP signaling pathway $[2,28,82]$. The PPAR signaling pathway was previously reported to affect ovarian follicle development and normal ovarian function by being indirectly involved in oocyte maturation and ovulation via regulation of steroid hormone synthesis in granulosa cell [74]. Accordingly, the key candidate genes such as NDUFAB1, $M C 2 R, V I P R 2$, GHRHR-LR, MC2R and SSTR2 that were identified currently may be implicated in granulosa cell proliferation and apoptosis, oocyte meiosis and maturation, follicular differentiation and atresia, and secretion of gonadotrophin-release hormone via crosstalk or intracellular interactions with the PPAR pathway $[61,79$, 83-86].

\section{Conclusions}

Collectively, the transcriptome comparative analysis of ovarian follicles at the GWF, SYF and LYF developmental stages reveals the key genes and signaling pathways involved in ovarian follicular follicle growth (including follicle selection), differentiation, and maturation, which has provided molecular evidences for new insight into the regulatory mechanism underlying ovarian follicle development associated with egg production in chicken.

\section{Methods}

Chicken raising management and trait measurement

After hatching, LB and JB hens were raised in layered batteries under the same rearing conditions, including free access to water and feed in accordance with the recommendations for nutrient levels of in Lohmann breeds 

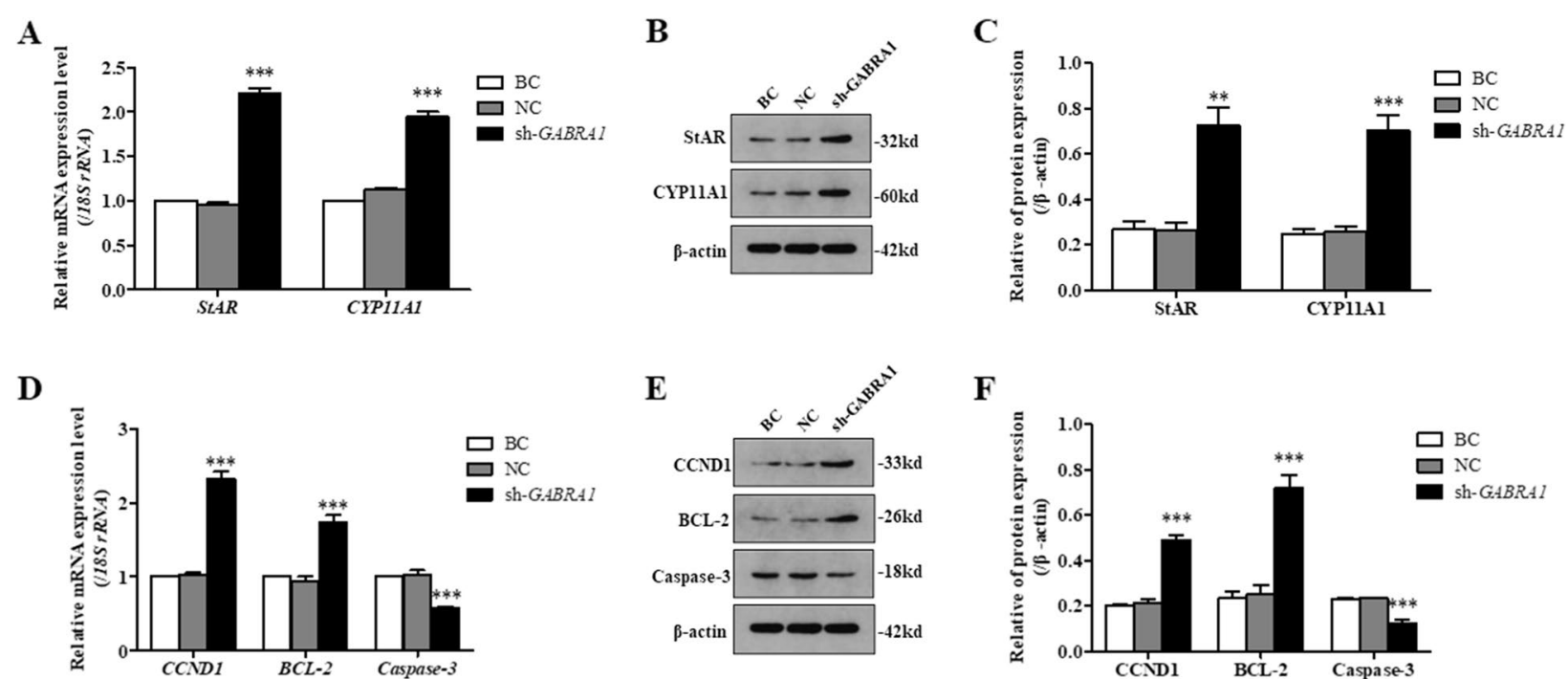

Fig. 8 Silence of GABRA1 in the GCs. sh-GABRA1, GCs being transfected with GABRA1-specific shRNA; NC, scrambled shRNA; BC, no shRNA as a vehicle. A The STAR and CYP11A1 mRNA expression in the GCs was analyzed using RT-qPCR. B, C Expression of STAR and CYP11A1 proteins in the GCs with or without interference using the shRNA was analyzed by western blotting; $\beta$-actin was used as a loading control. D The CCND1, BCL-2 and CASP3 mRNA expression in the GCs was analyzed using RT-qPCR. E, $\mathbf{F}$ Expression of CCND1, BCL-2 and caspase-3 proteins in the GCs with or without interference using the shRNA was analyzed by western blotting

[24, 87]. Approaching 16 weeks of age, hens were reared in individual cages under constantly maintained conditions. All of the layers were exposed to a $16 \mathrm{~L}: 8 \mathrm{D}$ photoperiod, with lights on at 5:00 AM. Age at first egg was recorded after the start of laying and egg production was observed daily, with egg weights determined on 1 day per week. Following feed and water restrictions at 21 and 66 weeks of age, BW was recorded and the individual laying performance calculated. Egg-laying traits examined in this study included hen-housed egg production (egglaying number) at $21,30,43,57$, and 66 weeks of age. Average egg production rates, average egg weight and body weight of LB and JB hens at the ages were calculated and compared.

\section{Samples preparation and cell culture}

In this study, ten layers of every JB and LB breeds were obtained and euthanized at 21 weeks of age, and the GWF, SYF and LWF follicles were harvested. After the surrounding vascular and connective tissues of the follicles were removed with fine forceps and a scalpel [88], follicles were immediately snapped frozen in liquid nitrogen and preserved at $-80^{\circ} \mathrm{C}$ for RNA extraction. All experiments and methods were performed in accordance with the ARRIVE guidelines.

The GCs from the SYFs were isolated and cultured in Medium199 (M199; Gibco, Waltham, MA, USA) supplemented with $10 \%(\mathrm{v} / \mathrm{v})$ fetal calf serum (Gibco) at $37^{\circ} \mathrm{C}$ with $5 \% \mathrm{CO}_{2}$ in humidified chambers following our published method $[8,89]$. The cultured GCs used in this experiment have been purified and quantified in our laboratory. The specificity of the GCs has been identified by the $\mathrm{H} \& \mathrm{E}$ staining procedure and fluorescence staining analysis $[25,90]$.

Total RNA was isolated from follicles of each hen using Trizol Reagent (Invitrogen Life Technologies, Carlsbad, CA, USA) according to the recommended manufacturer's protocol, and concentration, quality, and integrity were determined by a Thermo NanoDrop 8000 Spectrophotometer (Thermo Fisher Scientific, Wilmington, Delaware, USA). Three micrograms of RNA were used as input material for RNA sample preparations. The other parts of the samples were stored at $-80^{\circ} \mathrm{C}$ for validation experiments.

\section{RNA-Seq analysis}

The 18 cDNA libraries were generated using the TruSeq RNA Sample Preparation Kit (Illumina, San Diego, CA, USA) according to the method published by our group [23]. Among them, nine cDNA libraries corresponding to the GWF (named A11, A12, A13), SYF (named A21, A22, A23) and LYF (named A31, A32, A33) samples from LB hens and nine cDNA libraries corresponding to the GWF (named B11, B12, B13), SYF (named B21, B22, B23) and LYF (named B31, B32, B33) samples from JB layers were constructed, respectively. Effective concentration of libraries were greater than $2 \mathrm{nM}$ and libraries were 

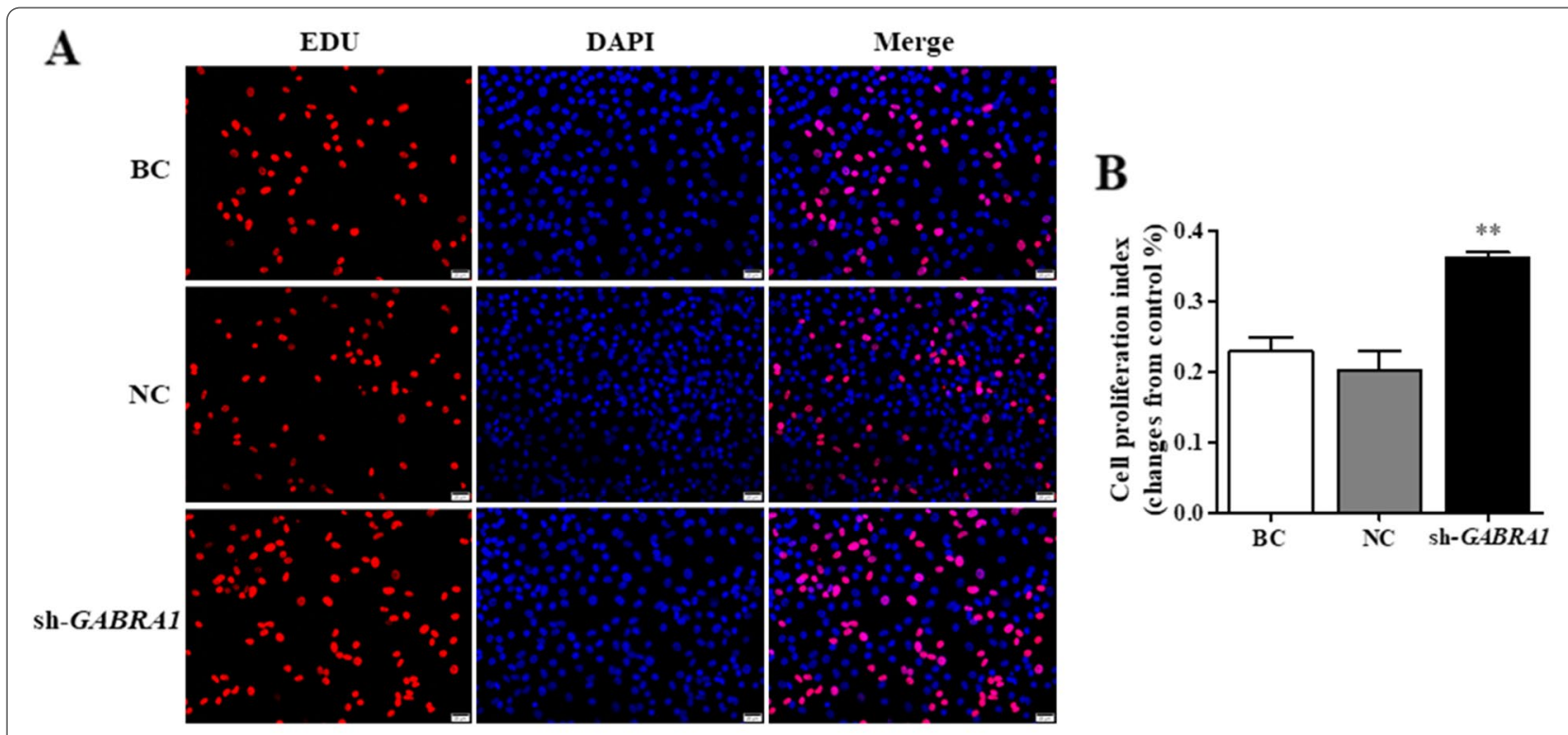

C

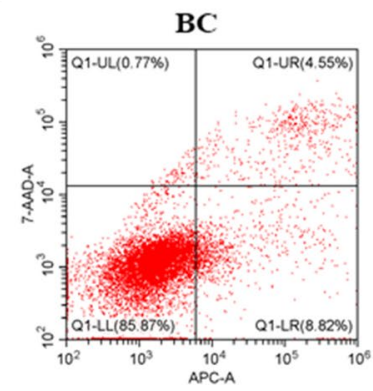

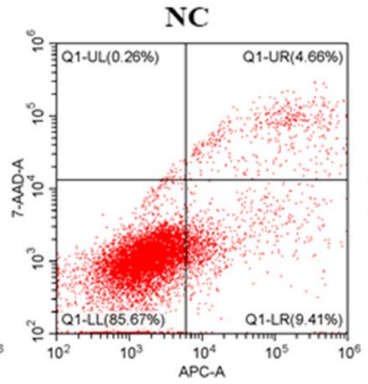

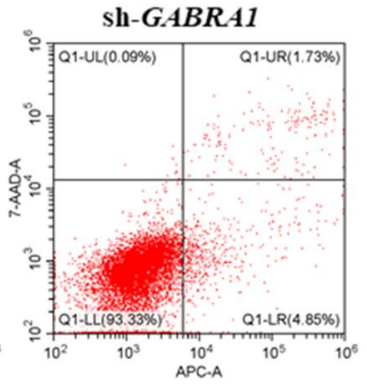

D

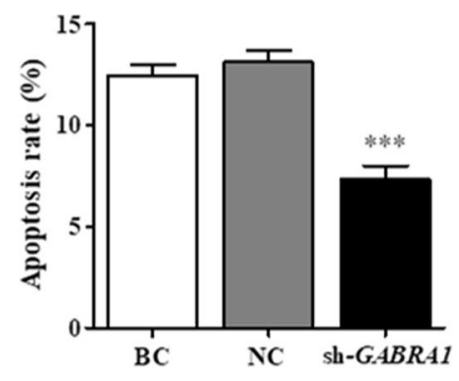

Fig. 9 Effects of GABRA1 silence on the GC proliferation and apoptosis. sh-GABRA1, GCs were transfected with GABRA1-specific shRNA; NC, scrambled shRNA; BC, no shRNA as a vehicle. A, B GABRA1 silence on the GC proliferation. C, D GABRA1 silence on cell apoptosis

qualified, sequenced, and paired-end sequencing with the $150 \mathrm{bp}$ sequencing read length was performed. The cDNA libraries were sequenced on a Hiseq platform (Illumina, Inc., San Diego, CA, USA) by Shanghai Personal Biotechnology Cp. Ltd. Follow-up analyses were based on clean data with high quality. All of the clean reads were aligned with the reference genome (ftp://ftp.ensembl.org/pub/ release-86/fasta/gallusgallus/dna/Gallusgallus.Gallusgall us-5.0.dna.toplevel.fa.gz) by using sequence alignment program HISAT 2.1.0 [91, 92].

\section{Identification of differentially expressed genes}

In accordance with our earlier reported method [23], the HTSeq (ver. 0.6.1) software was utilized to count the reads mapped to each gene. The transcription level was normalized according to its FPKM (Fragments per Kilobase of transcript per Million mapped reads) values using the Cufflinks package (v2.1.1). And based upon the normalized FPKM +1 value, expression pattern assessment for differentially expressed genes (DEGs) between case group and control group was fulfilled by using the MultiExperiment Viewer (version 4.9.0) software (https://sourc eforge.net/projects/mev-tm4/files/latest/download). The resulting $p$-values were adjusted using the Benjamini and Hochberg's approach for controlling the false discovery rate and an absolute value of the $\mid \log _{2}$ FoldChange $\mid$ $\left(\log _{2} \mathrm{FC}\right)$ was served as the threshold for judging significance of the gene expression. Candidate genes with an adjusted $p$-value (padj) $<0.05$ and $\log _{2} \mathrm{FC}>1$ were identified as differentially expressed. MA plots to visualize upand down-regulated genes of each sample were generated by using the R package "ggplot2" (version 3.5.0), according to the values of padj and $\log _{2} \mathrm{FC}$ [93].

\section{GO annotation and KEGG enrichment analysis for DEGs}

An online biological tool, Gene Ontology (GO, http:// geneontology.org/), was utilized to annotate and analyze the molecular and functional characteristics of the DEGs [94]. The calculated $p$-value was Bonferroni corrected, taking the corrected $p$-value $<0.05$ as a threshold 
for GO annotation. Another online biological tool, Kyoto Encyclopedia of Genes and Genomes (KEGG, http:// www.kegg.jp/), provided the comprehensive database resources for the KEGG pathway enrichment of the DEGs. In this step, four databases were utilized to reveal high-level functions and biological systems of the DEGs, including Reactome (http://www.reactome.org), KEGG pathway (http://www.genome.jp/kegg/). Results with $P<0.05$ were considered significantly enriched by DEG.

\section{Data validation by quantitative real-time RT-PCR}

To verify the accuracy and repeatability of the RNASeq results of DEGs, transcription levels of 24 representative genes in the ovarian follicles were estimated by using quantitative real-time reverse transcriptase PCR (RT-qPCR) as described previously [8]. The primers utilized for amplification of the candidate genes including VIPR2, GABRA1, PERP1, ZP1, and WISP12, et al., were listed in Table 5 . Using the $2^{-\Delta \Delta \mathrm{Ct}}$ method, mRNA expression results were normalized against $18 \mathrm{~S}$ $r R N A$ as internal control. To quantify mRNA expression levels by RT-qPCR analysis, four amplified products in independent reactions per bird were utilized. All the experiments were carried out in triplicate using different batches of sampled follicles.

\section{Small hairpin RNA (shRNA) transfection}

Three small interfering (siRNA) sequences targeting NDUFAB1 or GABRA1 gene were designed using an InvivoGen siRNA Wizard v3.1 and the most effective siRNA was screened out as we previously reported [8, 89]. After lentiviral expression vector pLVX-shRNA2NDUFAB1 or -GABRA1 carrying the specific siRNA was constructed, GCs were then transfected with the $N D U$ FAB1 shRNA or GABRA1 shRNA lentivirus in 24-well plates $\left(2 \times 10^{5}\right.$ cells/well), respectively; and incubated at $37^{\circ} \mathrm{C}$ with $5 \% \mathrm{CO}_{2}$. After $24 \mathrm{~h}$ of culture, the GCs were collected for EdU cell proliferation and cell apoptosis assay, and lysed for Western blotting and RT-qPCR analysis. The sequence information of NDUFAB1 shRNA, GABRA1 shRNA, shRNA negative control and the frame of lentiviral vectors was shown in Table S2. The most effective siRNA sequences were listed as below: $N D U$ FAB1 siRNA 5'-CCACAAGAGAUAGUAGAUUTT-3';

Table 5 Primer pairs designed for quantitative real-time PCR analysis

\begin{tabular}{|c|c|c|c|c|}
\hline Gene & Forward primer $\left(5^{\prime}-3^{\prime}\right)$ & Reverse primer $\left(5^{\prime}-3^{\prime}\right)$ & Accession No. & Size \\
\hline VIPR2 & ATAATGACTATGAGGACGAT & TGGATGTAGTTCCGAGTA & NM_001014970 & $154 \mathrm{bp}$ \\
\hline GABRA1 & TGTGTTTTCTGCCCTCATC & ATCCTTCACCTTCTTTGGC & NM_204318 & $109 \mathrm{bp}$ \\
\hline PERP1 & AGACCTTGCCCTATGTGC & GAAGTTGAACCGAAGTGTAT & NM_001277703 & $206 \mathrm{bp}$ \\
\hline$Z P 1$ & CTCCACCATTGATGTCCAGC & TCGGCGTCAGGGTAGTAGG & NM_204683 & $222 \mathrm{bp}$ \\
\hline WISP1 & CCAGGATTTCCAACGACA & GACAGCCAGGCACTTCTT & NM_001024579 & $122 b p$ \\
\hline$M C 2 R$ & TCTTCTACGCTTTGCGGTAC & ACTGGTTGGCAGTGAGGC & NM_001031515 & $245 \mathrm{bp}$ \\
\hline STARD4 & AATGGACATCGTGGAAAC & AGGCTGTGGCTAGGATAG & NM_001079742 & $249 \mathrm{bp}$ \\
\hline NDUFAB1 & AGGACGAGTTCGGCTTTG & TGACATCAGGGCCATCC & XM_004945263 & $157 \mathrm{bp}$ \\
\hline$B C L 2 L 14$ & TAAGGAACACGCAGAATC & TGTAGGAGCAGTCGCAAG & XM_040660909 & $231 \mathrm{bp}$ \\
\hline LOC424014 & TGAGGATGGCTCGGTTGA & AATGGTGTAGGTGCTGATGG & XM_001232693 & $130 \mathrm{bp}$ \\
\hline$A D R B 2$ & GGAGCGACTACAACGAGG & AATCACTTCCCAAGCAACC & XM_040683024 & $255 \mathrm{bp}$ \\
\hline PRLL & GCAGTAGATGAAGCGATGT & GCCATACCCAACTCCCAC & NM_001165912 & $172 \mathrm{bp}$ \\
\hline HSD17B1 & CACCGCACGCACCATTCA & CGCACTCCACCAGCGTCAT & NM_204837 & $206 \mathrm{bp}$ \\
\hline NCAM2 & CGGCTACAAACAGAATAGGAA & ATGAATGAAACCTTGGCAGT & XM_425540 & $124 \mathrm{bp}$ \\
\hline CYP2D6 & TTACTACAACCCGCATCT & AAGGACTTCTTTCCCATC & NM_001195557 & 297 bp \\
\hline $\mathrm{CRH}$ & CTGGACCTGACTTTCCACCTGC & CCGCCTCACTTCCCGATGA & NM_001123031 & $116 \mathrm{bp}$ \\
\hline GHRHR-LR & TGGCATTCTTCCAGTTCA & GACCCAAGTAAGCATCACAG & XM_040664932 & $167 \mathrm{bp}$ \\
\hline 104 & ACAAGCGGGTCAGCAAAGTG & TACCGGGTCGGTGTTGAGGG & NM_204282 & $179 \mathrm{bp}$ \\
\hline SSTR2 & CCAACTCGGAGCCAAGAC & CAAAGGGAGCAGTCAAACA & NM_001030345 & $164 \mathrm{bp}$ \\
\hline CDKN1A & GACCACGGAAGGGACTGA & AGACGGTGACGGACCACA & NM_204396 & $129 \mathrm{bp}$ \\
\hline STAR & GTCCCTCGCAGACCAAGT & TCCCTACTGTTAGCCCTGA & NM_204686 & $196 \mathrm{bp}$ \\
\hline CYP11A1 & GCTTTGCCTTGGAGTCTGTG & TCGGTGCTCTTGCGTTGC & NM_001001756 & $277 b p$ \\
\hline CCND1 & GGAGCAGAAGTGCGAAGAGG & TGGAGTTGTCGGTGTAAATG & NM_205381 & $188 \mathrm{bp}$ \\
\hline$B C L-2$ & ATGACCGAGTACCTGAACCG & CCAAGATAAGCGCCAAGAGT & NM_205339 & $182 \mathrm{bp}$ \\
\hline CASP3 & AAGAACTTCCACCGAGATACCG & GCTTAGCAACACACAAACAAAA & NM_204725 & $204 b p$ \\
\hline $18 S$ rRNA & ATTGGAGGGCAAGTCTGGTG & CCAGCTCGATCCCAAGATCC & AF173612 & $109 \mathrm{bp}$ \\
\hline
\end{tabular}


GABRA1 siRNA 5' - GCAGAAUGUCCAAUGCAUUTT$3^{\prime}$. Scrambled siRNA was used as the negative control siRNA: 5' - UUCUCCGAACGUGUCACGUTT-3', which was synthesized by Genepharma (Shanghai, China).

\section{Western blotting}

Western blot analysis for STAR, CYP11A1, CCND1, BCL-2, and Caspaes-3 was performed using total cellular extracts according to our previously described $[8,89]$. The affinity-purified antibodies for STAR and the other antibodies were used (Supplementary Table S3). Briefly, equal amounts of protein were separated by $10 \%(\mathrm{w} / \mathrm{v})$ SDS-polyacrylamide gel under reducing conditions and electro-transferred to Protran nitrocellulose membranes (Whatman, Dassel, Germany). After electrophoresis of the protein samples in a mini gel apparatus, a pre-stained protein molecular weight marker was loaded to locate/ monitor the target proteins in the electrophoresis (SDSPAGE). At the approximated protein size position, the gel was directly cut and transferred to the nitrocellulose membrane for western blotting. The horseradish peroxidase-conjugated anti-rabbit or anti-mouse IgG secondary antibody was incubated for $2 \mathrm{~h}$ at room temperature. Blots were subsequently performed with ECL western blotting agent (Rockford, IL, USA) for $5 \mathrm{~min}$ and exposed to X-ray film for $1-5 \mathrm{~min}$. The signals were detected using the ECL Plus Western blotting detection system according to the manufacturer's instructions. Anti- $\beta$-actin (dilution 1:500, Boster, Wuhan, China) antibody acted as a loading control. As a result, the molecular size of the ladders was not observed in the original blots.

\section{EdU cell proliferation assay}

Following the shRNA transfection of the GCs with $N D U$ $F A B 1$ or $G A B R A 1$ silence, a variation in cell proliferation was determined by EdU (5'-Ethynyl-2'- deoxyuridine) incorporation assay using the Cell-Light EdU imaging kit (RiboBio, Guangzhou, China) according to the manufacturer's protocol. Each experiment was performed in triplicate and repeated five times. The number of EdUpositive cells was expressed as a percentage and calculated relative to the total number of cells (positive cells/ total cells in one field) as previously described [8]. The ratio of positive cells was calculated from the average of the five group values.

\section{Cell apoptosis assay}

The apoptosis of GCs was determined by flow cytometry (BD Biosciences, USA) using the Annexin VAllophycocyanin(APC)/7-amino-actinomycin D (AAD) Apoptosis Detection Kit (KeyGEN, Nanjing, China), in accordance with the manufacturer's protocols. The apoptosis rate of GCs was estimated, i.e., total number of apoptotic cells comprises the number of cells in the right upper quadrant (Q1-UR) and number of cells in the right lower quadrant (Q1-LR), and analyzed using FlowJo v7.6 software (Stanford University, Stanford, CA, USA). Each experiment was carried out for at least three times.

\section{Statistical analysis}

Statistical analysis was fulfilled using the SPSS12.0 software package [95]. Data were analyzed by executing a Student's $t$-test for comparisons between the RNA-Sequencing and RT-qPCR determination after confirmation of normal distributions for non-parametric analysis. Values were presented as mean \pm SEM and bars with superscript symbols that indicate the significant difference compared with control groups at ${ }^{* * * *} p<0.001, * * 0<0.01,{ }^{*} p<0.05$.

\section{Abbreviations}

NDUFAB1: NADH: ubiquinone oxidoreductase subunit AB; GABRA1: Gammaaminobutyric acid type A receptor alpha1 subunit; STAR: Steroidogenic-related enzymes steroidogenic acute regulatory protein; HSD17B1: Hydroxysteroid (17beta) dehydrogenase 1; P450scc/CYP11A1: Cytochrome P450 side-chain cleavage; P4: Progesterone; E2: Estradiol; AMH: Anti-müllerian hormone; CCND1: Cyclin D1; CASP3: Caspase-3; BCl-2: B-cell lymphoma-2; GO: Gene ontology; KEGG: Kyoto encyclopedia of genes and genomes; GWF: Growing white follicle; SYF: Small yellow follicle; LYF: Large yellow follicle; DEG: Differentially expressed gene; GC: Granulosa cell; JB: Jilin Black chicken; LB: Lohmann Brown chicken; siRNA: Small interfering RNA; shRNA: Small hairpin RNA; EdU: 5'-Ethynyl-2'- deoxyuridine; APC: Annexin V-Allophycocyanin; AAD: 7-amino-actinomycin D; AF: Age at first egg; BW: Body weight; EW: Egg weight; $\mathrm{HH}$ : Hen-housed egg production; EN: Egg numbers per hen; CAMP: Adenosine-3', 5'-cyclic monophosphate; CAM: Cell adhesion molecule; AMPK: AMP-activated protein kinase; FSH: Follicle stimulating hormone (FSH); FSHR: FSH receptor; PACAP: Adenylate cyclase-activating polypeptide; VIP: Vasoactive intestinal peptide; PAC1: PACAP type I receptor; VIPR: VIP receptor; TC: Theca cell; ADRB2: $\beta 2$ adrenergic receptor; PKA: Protein kinase A; PKC: Protein kinase C; PLC: Phospholipase C; CREB: CAMP response element-binding protein;

PCOS: Polycystic ovary syndrome; ACP: Acyl carrier protein.

\section{Supplementary Information}

The online version contains supplementary material available at https://doi. org/10.1186/s12864-021-08213-w.

Additional file 1: Supplementary Table S1. Results of the cleaned data of reads filtered and the reads mapped. Supplementary Table S2. Construction frame of lentiviral vectors against NDUFAB1 and GABRA1 genes. Supplementary Table S3. Antibodies used for western blot analysis. Supplementary Figure S1. The oxidative phosphorylation pathway (gga: 00190) and its components. Supplementary Figure S2. The neuroactive ligand-receptor interaction pathway (gga: 04080) and its components. Supplementary Figure S3. The images show the original gels of western blot in the Fig. 6B and Fig. 6E. Supplementary Figure S4. The images show the original gels of western blot in the Fig. $8 \mathrm{~B}$ and Fig. $8 \mathrm{E}$.

\section{Acknowledgements}

We would like to thank the help of sequencing analysis from Personal Biotechnology Co., Ltd. Shanghai, China.

Authors' contributions

$X S$ and XXC contributed equally to this manuscript. XS and XXC mainly performed the experiments; JHZ, CM, CCY and SL analyzed the data, and helped 
perform some experiments; RFX conceived, designed the experiments, and wrote the manuscript; NQ designed the experiments and revised the manuscript. All authors read and approved the final manuscript.

\section{Funding}

RFX is funded by grants from the National Natural Science Foundation of China (Grant No.32172714, No.31672407), the Project of Science and Technology Development Plan of Jilin Province (No. 20170101019JC), and the China Agriculture Research System of MOF and MARA (No.CARS-41-Z03). NQ is funded by grants from the National Natural Science Foundation of China (Grant No.31902145), and the Project of Education Development Plan of Jilin Province (No. JJKH20180646KJ).

\section{Availability of data and materials}

The relevant datasets have been published by our group and are available at PRJNA669967 (https://dataview.ncbi.nlm.nih.gov/object/PRJNA669967? reviewer=r19gd76c8kfv73u2c0r3ruc4vm) and PRJNA670553 (https://datav iew.ncbi.nlm.nih.gov/object/PRJNA670553?reviewer=3fu2up8dl58afnlahsue 09njcp) in NCBI [23].

\section{Declarations}

\section{Ethics approval and consent to participate}

This study is in accordance with ARRIVE guidelines. All procedures executed in chickens were approved by the Institutional Animal Care and Use Committee (IACUC) of Jilin Agricultural University (Changchun, China). Ethical approval for animal survival was given by the Animal Ethics Committee of Jilin Agricultural University (Changchun, China). All birds were sacrificed prior to the removal of organs based upon the IACUC Guidelines for the euthanasia of experimental animals (Permission No. GR (J) 19-030).

\section{Consent for publication}

Not applicable.

\section{Competing interests}

The authors declare that they have no competing interests.

\section{Author details}

${ }^{1}$ Joint Laboratory of Modern Agricultural Technology International Cooperation, Ministry of Education, Jilin Agricultural University, Changchun 130118, China. ${ }^{2}$ Department of Animal Genetics, Breeding and Reproduction, College of Animal Science and Technology, Jilin Agricultural University, Changchun 130118, China.

Received: 4 July 2021 Accepted: 26 November 2021

Published online: 15 December 2021

\section{References}

1. Johnson PA. Follicle selection in the avian ovary. Reprod Domest Anim. 2012:47(Suppl 4):283-7.

2. Johnson AL. Ovarian follicle selection and granulosa cell differentiation. Poult Sci. 2015;94(4):781-5.

3. Brady K, Porter TE, Liu HC, Long JA. Characterization of the hypothalamopituitary-gonadal axis in low and high egg producing Turkey hens. Poult Sci. 2020;99(2):1163-73.

4. Tilly JL, Kowalski KI, Johnson AL. Stage of ovarian follicular development associated with the initiation of steroidogenic competence in avian granulosa cells. Biol Reprod. 1991;44(2):305-14.

5. Klein-Hessling H. Managing breeder hens for more eggs. World Poultry. 2007;23(5):16-7.

6. Woods DC, Johnson AL. Regulation of follicle-stimulating hormonereceptor messenger RNA in hen granulosa cells relative to follicle selection. Biol Reprod. 2005;72(3):643-50.

7. Shen M, Li T, Chen F, Wu P, Wang Y, Chen L, et al. Transcriptomic analysis of circRNAs and mRNAs reveals a complex regulatory network that participate in follicular development in chickens. Front Genet. 2020;11:503.

8. Xu R, Qin N, Xu X, Sun X, Chen X, Zhao J. Inhibitory effect of SLIT2 on granulosa cell proliferation mediated by the CDC42-PAKs-ERK1/2 MAPK pathway in the prehierarchical follicles of the chicken ovary. Sci Rep. 2018;8(1):9168.

9. Johnson AL, Solovieva EV, Bridgham JT. Relationship between steroidogenic acute regulatory protein expression and progesterone production in hen granulosa cells during follicle development. Biol Reprod. 2002;67(4):1313-20.

10. Sechman A, Pawlowska K, Hrabia A. Effect of 3,3',5-triiodothyronine and 3,5-diiodothyronine on progesterone production, CAMP synthesis, and mRNA expression of STAR, CYP11A1, and HSD3B genes in granulosa layer of chicken preovulatory follicles. Domest Anim Endocrinol. 2011:41(3):137-49.

11. Ocón-Grove OM, Poole DH, Johnson AL. Bone morphogenetic protein 6 promotes FSH receptor and anti-Müllerian hormone mRNA expression in granulosa cells from hen prehierarchal follicles. Reproduction. 2012;143(6):825-33.

12. Huang J, Cui H, Peng X, Fang J, Zuo Z, Deng J, et al. The association between splenocyte apoptosis and alterations of Bax, BCl-2 and caspase-3 mRNA expression, and oxidative stress induced by dietary nickel chloride in broilers. Int J Environ Res Public Health. 2013;10(12):7310-26.

13. Heinosalo T, Saarinen N, Poutanen M. Role of hydroxysteroid (17beta) dehydrogenase type 1 in reproductive tissues and hormone-dependent diseases. Mol Cell Endocrinol. 2019;489:9-31.

14. Yang KT, Lin CY, Huang HL, Liou JS, Chien CY, Wu CP, et al. Expressed transcripts associated with high rates of egg production in chicken ovarian follicles. Mol Cell Probes. 2008;22(1):47-54.

15. Diaz FJ, Anthony K, Halfhill AN. Early avian follicular development is characterized by changes in transcripts involved in steroidogenesis, paracrine signaling and transcription. Mol Reprod Dev. 2011;78(3):212-23.

16. Wang Y, Chen Q, Liu Z, Guo X, Du Y, Yuan Z, et al. Transcriptome analysis on single small yellow follicles reveals that Wnt 4 is involved in chicken follicle selection. Front Endocrinol (Lausanne). 2017;8:317.

17. Chen Q, Wang Y, Liu Z, Guo X, Sun Y, Kang L, et al. Transcriptomic and proteomic analyses of ovarian follicles reveal the role of VLDLR in chicken follicle selection. BMC Genomics. 2020;21(1):486.

18. Zhong C, Liu Z, Qiao X, Kang L, Sun Y, Jiang Y. Integrated transcriptomic analysis on small yellow follicles reveals that Sosondowah Ankyrin repeat domain family member a inhibits chicken follicle selection. Anim Biosci. 2021;34(8):1290-302.

19. Wang Y, Shi H, Zhang G, Wu P, Chen L, Shen M, et al. Transcriptome analysis of long noncoding RNAs and mRNAs in granulosa cells of Jinghai yellow chickens illuminated with red light. Front Genet. 2021;12:563623.

20. Luan X, Liu D, Cao Z, Luo L, Liu M, Gao M, et al. Transcriptome profiling identifies differentially expressed genes in Huoyan goose ovaries between the laying period and ceased period. PLoS One. 2014;9(11):e113211.

21. Ren J, Sun C, Chen L, Hu J, Huang X, Liu X, et al. Exploring differentially expressed key genes related to development of follicle by RNA-seq in Peking ducks (Anas Platyrhynchos). PLoS One. 2019;14(6):e0209061.

22. Brady K, Liu HC, Hicks JA, Long JA, Porter TE. Transcriptome analysis during follicle development in Turkey hens with low and high egg production. Front Genet. 2021:12:619196.

23. Chen X, Sun X, Chimbaka IM, Qin N, Xu X, Liswaniso S, et al. Transcriptome analysis of ovarian follicles reveals potential pivotal genes associated with increased and decreased rates of chicken egg production. Front Genet. 2021;12:622751.

24. Lohmann Tierzucht GmBH. Management guide for laying hens: Lohmann Brown-classic. Cuxhaven: Lohmann Tierzucht GmbH; 2005.

25. Qin N, Fan XC, Xu XX, Tyasi TL, Li SJ, Zhang YY, et al. Cooperative effects of FOXL2 with the members of TGF- $\beta$ superfamily on FSH receptor mRNA expression and granulosa cell proliferation from hen prehierarchical follicles. PLoS One. 2015;10(10):e0141062.

26. Gilchrist RB, Ritter LJ, Myllymaa S, Kaivo-Oja N, Dragovic RA, Hickey $T E$, et al. Molecular basis of oocyte-paracrine signaling that promotes granulosa cell proliferation. J Cell Sci. 2006;1 19(Pt 18):3811-21.

27. Woodruff TK, Shea LD. The role of the extracellular matrix in ovarian follicle development. Reprod Sci. 2007;14(Suppl 8):6-10.

28. Johnson AL, Woods DC. Dynamics of avian ovarian follicle development: cellular mechanisms of granulosa cell differentiation. Gen Comp Endocrinol. 2009;163(1-2):12-7. 
29. Son WY, Das M, Shalom-Paz E, Holzer H. Mechanisms of follicle selection and development. Minerva Ginecol. 2011;63(2):89-102.

30. Conconi MT, Spinazzi R, Nussdorfer GG. Endogenous ligands of PACAP/ VIP receptors in the autocrine-paracrine regulation of the adrenal gland. Int Rev Cytol. 2006;249:1-51.

31. Dickson L, Finlayson K. VPAC and PAC receptors: from ligands to function. Pharmacol Ther. 2009;121(3):294-316.

32. Heindel JJ, Sneeden J, Powell CJ, Davis B, Culler MD. A novel hypothalamic peptide, pituitary adenylate cyclase-activating peptide, regulates the function of rat granulosa cells in vitro. Biol Reprod. 1996;54(3):523-30

33. Apa R, Lanzone A, Miceli F, Vaccari S, Macchione E, Stefanini M, et al. Pituitary adenylate cyclase-activating polypeptide modulates plasminogen activator expression in rat granulosa cell. Biol Reprod. 2002;66(3):830-5.

34. Vaccari S, Latini S, Barberi M, Teti A, Stefanini M, Canipari R. Characterization and expression of different pituitary adenylate cyclase-activating polypeptide/vasoactive intestinal polypeptide receptors in rat ovarian follicles. J Endocrinol. 2006;191(1):287-99.

35. Zhou R, Tsang AH, Lau SW, Ge W. Pituitary adenylate cyclase-activating polypeptide (PACAP) and its receptors in the zebrafish ovary: evidence for potentially dual roles of PACAP in controlling final oocyte maturation. Biol Reprod. 2011;85(3):615-25.

36. Lara HE, Dissen GA, Leyton V, Paredes A, Fuenzalida H, Fiedler JL, et al. An increased intra-ovarian synthesis of nerve growth factor and its low affinity receptor is a principal component of steroid-induced polycystic ovary in the rat. Endocrinology. 2000;141(3):1059-72.

37. Parra C, Fiedler JL, Luna SL, Greiner M, Padmanabhan V, Lara HE. Participation of vasoactive intestinal polypeptide in ovarian steroids production during the rat estrous cycle and in the development of estradiol valerateinduced polycystic ovary. Reproduction. 2007;133(1):147-54.

38. Mayerhofer A, Dissen GA, Costa ME, Ojeda SR. A role for neurotransmitters in early follicular development: induction of functional follicle-stimulating hormone receptors in newly formed follicles of the rat ovary. Endocrinology. 1997;138(8):3320-9.

39. Merz C, Saller S, Kunz L, Xu J, Yeoman RR, Ting AY, et al. Expression of the beta-2 adrenergic receptor (ADRB-2) in human and monkey ovarian follicles: a marker of growing follicles? J Ovarian Res. 2015;8:8.

40. Thaker PH, Han LY, Kamat AA, Arevalo JM, Takahashi R, Lu C, et al. Chronic stress promotes tumor growth and angiogenesis in a mouse model of ovarian carcinoma. Nat Med. 2006;12(8):939-44.

41. Kang Y, Nagaraja AS, Armaiz-Pena GN, Dorniak PL, Hu W, Rupaimoole R, et al. Adrenergic stimulation of DUSP1 impairs chemotherapy response in ovarian cancer. Clin Cancer Res. 2016;22(7):1713-24.

42. Hatefi A, Zare Shahneh A, Ansari Pirsaraie Z, Alizadeh AM, Atashnak MP, Masoudi R, et al. The stimulation and inhibition of beta-2 adrenergic receptor on the inflammatory responses of ovary and immune system in the aged laying hens. BMC Vet Res. 2021;17(1):195.

43. Barria A, Leyton V, Ojeda SR, Lara HE. Ovarian steroidal response to gonadotropins and beta-adrenergic stimulation is enhanced in polycystic ovary syndrome: role of sympathetic innervation. Endocrinology. 1993;133(6):2696-703

44. Wang Y, Fu X, Xu J, Wang Q, Kuang H. Systems pharmacology to investigate the interaction of berberine and other drugs in treating polycystic ovary syndrome. Sci Rep. 2016;6:28089.

45. Labrie F, Luu-The V, Lin SX, Labrie C, Simard J, Breton R, et al. The key role of 17 beta-hydroxysteroid dehydrogenases in sex steroid biology. Steroids. 1997;62(1):148-58.

46. Poutanen $M$, Isomaa V, Peltoketo $H$, Vihko R. Role of 17 beta-hydroxysteroid dehydrogenase type 1 in endocrine and intracrine estradiol biosynthesis. J Steroid Biochem Mol Biol. 1995;55(5-6):525-32.

47. Andersson S, Moghrabi N. Physiology and molecular genetics of 17 betahydroxysteroid dehydrogenases. Steroids. 1997;62(1):143-7.

48. Hilborn E, Stål O, Jansson A. Estrogen and androgen-converting enzymes $17 \beta$-hydroxysteroid dehydrogenase and their involvement in cancer: with a special focus on 17ß-hydroxysteroid dehydrogenase type 1,2, and breast cancer. Oncotarget. 2017:8(18):30552-62.

49. Delvoux B, D'Hooghe T, Kyama C, Koskimies P, Hermans RJ, Dunselman $G A$, et al. Inhibition of type $117 \beta$-hydroxysteroid dehydrogenase impairs the synthesis of $17 \beta$-estradiol in endometriosis lesions. J Clin Endocrinol Metab. 2014;99(1):276-84.
50. Vihko P, Herrala A, Härkönen P, Isomaa V, Kaija H, Kurkela R, et al. Control of cell proliferation by steroids: the role of $17 \mathrm{HSDs}$. Mol Cell Endocrinol. 2006:248(1-2):141-8.

51. Barberi M, Muciaccia B, Morelli MB, Stefanini M, Cecconi S, Canipari R. Expression localisation and functional activity of pituitary adenylate cyclase-activating polypeptide, vasoactive intestinal polypeptide and their receptors in mouse ovary. Reproduction. 2007;134(2):281-92.

52. Zhou M, Lei M, Rao Y, Nie Q, Zeng H, Xia M, et al. Polymorphisms of vasoactive intestinal peptide receptor-1 gene and their genetic effects on broodiness in chickens. Poult Sci. 2008;87(5):893-903.

53. Zhou M, Du Y, Nie Q, Liang Y, Luo C, Zeng H, et al. Associations between polymorphisms in the chicken VIP gene, egg production and broody traits. Br Poult Sci. 2010;51(2):195-203.

54. Barrera NP, Betts J, You H, Henderson RM, Martin IL, Dunn SM, et al. Atomic force microscopy reveals the stoichiometry and subunit arrangement of the alpha4beta3delta GABA(A) receptor. Mol Pharmacol. 2008;73(3):960-7.

55. Chuang SH, Reddy DS. Genetic and molecular regulation of extrasynaptic GABA-A receptors in the brain: therapeutic insights for epilepsy. J Pharmacol Exp Ther. 2018;364(2):180-97.

56. Olsen RW, Sieghart W. GABA a receptors: subtypes provide diversity of function and pharmacology. Neuropharmacology. 2009;56(1):141-8.

57. Sigel E, Steinmann ME. Structure, function, and modulation of GABA(A) receptors. J Biol Chem. 2012;287(48):40224-31.

58. Sexton CA, Penzinger R, Mortensen M, Bright DP, Smart TG. Structural determinants and regulation of spontaneous activity in GABAA receptors. Nat Commun. 2021;12(1):5457.

59. Bixo M, Johansson M, Timby E, Michalski L, Bäckström T. Effects of GABA active steroids in the female brain with a focus on the premenstrual dysphoric disorder. J Neuroendocrinol. 2018;30(2). https://doi.org/10.1111/ jne.12553.

60. Tuem KB, Atey TM. Neuroactive steroids: receptor interactions and responses. Front Neurol. 2017;8:442.

61. Masud AJ, Kastaniotis AJ, Rahman MT, Autio KJ, Hiltunen JK. Mitochondrial acyl carrier protein (ACP) at the interface of metabolic state sensing and mitochondrial function. Biochim Biophys Acta Mol Cell Res. 2019;1866(12):118540.

62. Byers DM, Gong H. Acyl carrier protein: structure-function relationships in a conserved multifunctional protein family. Biochem Cell Biol. 2007;85(6):649-62.

63. Chan DI, Vogel HJ. Current understanding of fatty acid biosynthesis and the acyl carrier protein. Biochem J. 2010;430(1):1-19.

64. Hiltunen JK, Chen Z, Haapalainen AM, Wierenga RK, Kastaniotis AJ. Mitochondrial fatty acid synthesis - an adopted set of enzymes making a pathway of major importance for the cellular metabolism. Prog Lipid Res. 2010:49(1):27-45.

65. Johnson AL, Bridgham JT. Regulation of steroidogenic acute regulatory protein and luteinizing hormone receptor messenger ribonucleic acid in hen granulosa cells. Endocrinology. 2001;142(7):3116-24.

66. Tilly JL, Kowalski Kl, Johnson AL. Cytochrome P450 side-chain cleavage (P450scc) in the hen ovary. II. P450scc messenger RNA, immunoreactive protein, and enzyme activity in developing granulosa cells. Biol Reprod. 1991:45(6):967-74.

67. Robinson FE, Etches RJ. Ovarian steroidogenesis during follicular maturation in the domestic fowl (Gallus domesticus). Biol Reprod. 1986;35(5):1096-105.

68. Gutiérrez CG, Campbell BK, Webb R. Development of a long-term bovine granulosa cell culture system: induction and maintenance of estradiol production, response to follicle-stimulating hormone, and morphological characteristics. Biol Reprod. 1997;56(3):608-16.

69. Zalányi S. Progesterone and ovulation. Eur J Obstet Gynecol Reprod Biol. 2001;98(2):152-9.

70. Wilson SC, Sharp PJ. The effects of progesterone on oviposition and ovulation in the domestic fowl (Gallus domesticus). Br Poult Sci. 1976;17(2):163-73.

71. Luukkainen T, Heikinheimo O, Haukkamaa M, Lähteenmäki P. Inhibition of folliculogenesis and ovulation by the antiprogesterone RU 486. Fertil Steril. 1988;49(6):961-3.

72. Heikinheimo O, Gordon K, Williams RF, Hodgen GD. Inhibition of ovulation by progestin analogs (agonists vs antagonists): preliminary 
evidence for different sites and mechanisms of actions. Contraception. 1996;53(1):55-64.

73. Chang Y, Lin TY, Lu CW, Huang SK, Wang YC, Wang SJ. Xanthohumolinduced presynaptic reduction of glutamate release in the rat hippocampus. Food Funct. 2016;7(1):212-26.

74. Dupont J, Reverchon M, Cloix L, Froment P, Ramé C. Involvement of adipokines, AMPK, PI3K and the PPAR signaling pathways in ovarian follicle development and cancer. Int J Dev Biol. 2012;56(10-12):959-67.

75. Nemer A, Azab AN, Rimon G, Lamprecht S, Ben-Menahem D. Different roles of CAMP/PKA and PKC signaling in regulating progesterone and PGE2 levels in immortalized rat granulosa cell cultures. Gen Comp Endocrinol. 2018:269:88-95.

76. Pecorelli A, Leoni G, Cervellati F, Canali R, Signorini C, Leoncini S, et al. Genes related to mitochondrial functions, protein degradation, and chromatin folding are differentially expressed in lymphomonocytes of Rett syndrome patients. Mediat Inflamm. 2013;2013:137629.

77. Yu Z, Poppe JL, Wang X. Mitochondrial mechanisms of neuroglobin's neuroprotection. Oxidative Med Cell Longev. 2013;2013:756989.

78. Feng D, Witkowski A, Smith S. Down-regulation of mitochondrial acyl carrier protein in mammalian cells compromises protein lipoylation and respiratory complex I and results in cell death. J Biol Chem. 2009;284(17):11436-45.

79. Richards JS, Ascoli M. Endocrine, paracrine, and autocrine signaling pathways that regulate ovulation. Trends Endocrinol Metab. 2018;29(5):313-25.

80. Choi JH, Choi KC, Auersperg N, Leung PC. Gonadotropins upregulate the epidermal growth factor receptor through activation of mitogenactivated protein kinases and phosphatidyl-inositol-3-kinase in human ovarian surface epithelial cells. Endocr Relat Cancer. 2005;12(2):407-21.

81. Johnson AL. Reproduction in the female. In: Whittow GC, editor. Sturkie's avian physiology (fifth edition). New York: Academic Press; 2015. p. 569-96.

82. Simoni M, Gromoll J, Nieschlag E. The follicle-stimulating hormone receptor: biochemistry, molecular biology, physiology, and pathophysiology. Endocr Rev. 1997;18(6):739-73.

83. Amsterdam A, Keren-Tal I, Aharoni D. Cross-talk between cAMP and p53-generated signals in induction of differentiation and apoptosis in steroidogenic granulosa cells. Steroids. 1996:61(4):252-6.

84. Nakanishi T. Endocrine disruption induced by organotin compounds; organotins function as a powerful agonist for nuclear receptors rather than an aromatase inhibitor. J Toxicol Sci. 2008;33(3):269-76.

85. Liu YX, Zhang Y, Li YY, Liu XM, Wang XX, Zhang CL, et al. Regulation of follicular development and differentiation by intra-ovarian factors and endocrine hormones. Front Biosci (Landmark Ed). 2019:24:983-93.

86. Hanlon C, Ramachandran R, Zuidhof MJ, Bédécarrats GY. Should I lay or should I grow: photoperiodic versus metabolic cues in chickens. Front Physiol. 2020;1 1:707.

87. Thiele HH. Management recommendations for rearing pullets for alternative housing systems. Lohmann Inf. 2007:42(2):14-24.

88. Politis I, Wang L, Turner JD, Tsang BK. Changes in tissue-type plasminogen activator-like and plasminogen activator inhibitor activities in granulosa and theca layers during ovarian follicle development in the domestic hen. Biol Reprod. 1990:42(5-6):747-54.

89. Zhu H, Qin N, Xu X, Sun X, Chen X, Zhao J, et al. Synergistic inhibition of csal 1 and csal 3 in granulosa cell proliferation and steroidogenesis of hen ovarian prehierarchical development. Biol Reprod. 2019;101(5):986-1000.

90. Lyu Z, Qin N, Tyasi TL, Zhu H, Liu D, Yuan S, et al. The hippo/MST pathway member SAV1 plays a suppressive role in development of the prehierarchical follicles in hen ovary. PLoS One. 2016;11(8):e0160896.

91. Pertea M, Kim D, Pertea GM, Leek JT, Salzberg SL. Transcript-level expression analysis of RNA-seq experiments with HISAT, StringTie and Ballgown. Nat Protoc. 2016;1 1(9):1650-67.

92. Kim D, Paggi JM, Park C, Bennett C, Salzberg SL. Graph-based genome alignment and genotyping with HISAT2 and HISAT-genotype. Nat Biotechnol. 2019:37(8):907-15.

93. Wang L, Feng Z, Wang X, Wang X, Zhang X. DEGseq: an R package for identifying differentially expressed genes from RNA-seq data. Bioinformatics. 2010;26(1):136-8.
94. Ashburner M, Ball CA, Blake JA, Botstein D, Butler H, Cherry JM, et al. Gene ontology: tool for the unification of biology. The gene ontology consortium. Nat Genet. 2000;25(1):25-9.

95. Lin JB, Chen X, Liu MD. SPSS 11.0 statistical analysis actual practice design (in Chinese). Beijing: Chinese Railroad Publishing House, China; 2002.

\section{Publisher's Note}

Springer Nature remains neutral with regard to jurisdictional claims in published maps and institutional affiliations.
Ready to submit your research? Choose BMC and benefit from:

- fast, convenient online submission

- thorough peer review by experienced researchers in your field

- rapid publication on acceptance

- support for research data, including large and complex data types

- gold Open Access which fosters wider collaboration and increased citations

- maximum visibility for your research: over $100 \mathrm{M}$ website views per year

At BMC, research is always in progress.

Learn more biomedcentral.com/submissions 